Universidadede São Paulo

Faculdade de Filosofia, Ciências e Letras de Ribeirão Preto

Departamento de Física

Fator de aumento de dose em Radioterapia com nanopartículas: estudo por simulação Monte Carlo

Vinícius Fernando dos Santos

Ribeirão Preto - SP

2017 
Universidade de São Paulo

Faculdade de Filosofia, Ciências e Letras de Ribeirão Preto

Departamento de Física

\section{Fator de aumento de dose em Radioterapia com nanopartículas: estudo por simulação Monte Carlo}

Vinícius Fernando dos Santos

\footnotetext{
Dissertação apresentada ao Departamento de Física da Faculdade de Filosofia Ciências e Letras de Ribeirão Preto da USP, como parte das exigências para a obtenção do título de Mestre em Ciências.

Àrea de concentração: Física Aplicada à Medicina e Biologia

Orientadora: Prof ${ }^{a}$. Dr ${ }^{\mathrm{a}}$. Patrícia Nicolucci
}

VERSÃO ORIGINAL

Ribeirão Preto - SP 
Autorizo a reprodução e divulgação total ou parcial deste trabalho, por qualquer meio convencional ou eletrônico, para fins de estudo e pesquisa, desde que citada à fonte.

Catalogação da publicação

Departamento de Física

Faculdade de Filosofia, Ciências e Letras de Ribeirão Preto da Universidade de São Paulo

Dos Santos, Vinícius Fernando

Fator de aumento de dose em radioterapia com nanopartículas: estudo por simulação Monte Carlo, 2017.

59 p.:il.; $30 \mathrm{~cm}$

Dissertação de Mestrado, apresentada ao Departamento de Física da Faculdade de Filosofia, Ciências e Letras de Ribeirão Preto da Universidade de São Paulo Área de concentração: Física Aplicada à Medicina e Biologia.

Orientadora: $\operatorname{Prof}^{\mathrm{a}}$. $\mathrm{Dr}^{\mathrm{a}}$. Patrícia Nicolucci.

Palavras-chave: Radioterapia, nanopartícula de ouro, fator de aumento de dose, simulação Monte Carlo. 
Dedico este trabalho ao meus avós, minha mãe, minha esposa, familiares $e$ amigos... 


\section{Agradecimentos}

À Deus primeiramente, por me guiar diante de tantas decisões e me dar saúde e sabedoria para desenvolver este trabalho;

À Prof ${ }^{a} \operatorname{Dr}^{\mathrm{a}}$. Patrícia Nicolucci, pela orientação do presente trabalho, pela paciência, confiança e credibilidade em mim depositadas, a qual agregou conhecimentos e expandiu horizontes profissionais e pessoais;

À todos os meus familiares e amigos, cujo apoio sempre esteve presente em todos os momentos de minha vida e também nessa etapa da minha qualificação profissional;

À minha esposa Luiza, que sempre me apoiou e me encorajou em todos os desafios e horas difíceis, para que não desistisse em nenhum momento;

Aos professores e colegas do programa FAMB, pelo incentivo à pesquisa e ao desenvolvimento profissional;

À Prof ${ }^{\mathrm{a}}$. Dr ${ }^{\mathrm{a}}$. Cassiana pelas opiniões e sugestões para o trabalho e dicas de experiências profissionais durante nossos cafés;

Aos grandes amigos de laboratório que o CIDRA me concedeu, Ana, Camila, Carol, Fernanda, Franciely, Jaqueline, Laís, Matheus, entre outros;

Aos meus avós José e Maria(in memória) e minha mãe Silvana, por sempre me apoiar e acreditar nos meus objetivos e planos futuros, e sempre me ajudar nos momentos difíceis, me encorajando para continuar firme no meu objetivo;

Ao Hospital de Câncer de Barretos, por ceder todo apoio para desenvolvimento do trabalho, em especial a todos os amigos do departamento de Radioterapia desta instituição;

À todos aqueles que aqui não foram citados, mas contribuíram de forma direta ou indireta para o desenvolvimento deste trabalho. 


\section{Resumo}

Santos, Vinícius Fernando dos. Fator de aumento de dose em Radioterapia com nanopartículas: estudo por simulação Monte Carlo. 2017. Dissertação (Mestrado) Departamento de Física, Faculdade de Filosofia, Ciências e Letras de Ribeirão Preto, Universidade de São Paulo, Ribeirão Preto, 2017.

A incorporação de nanopartículas metálicas em tecidos tumorais tem sido estudada em Radioterapia devido ao aumento de dose que pode ser obtido no volume alvo do tratamento. Estudos indicam que nanopartículas de ouro (AuNP) estão entre as de maior viabilidade biológica para essas aplicações, devido ao baixo potencial tóxico. Além disso, estudos mostram que AuNP de alguns nanômetros até alguns micrômetros podem permear vasos sanguíneos que alimentam tumores, permitindo sua incorporação nas células tumorais. Desta forma, este trabalho visou estudar os fatores de aumento de dose obtidos em Radioterapia com AuNP incorporadas ao tecido tumoral utilizando feixes de ortovoltagem, de braquiterapia e de teleterapia. Este trabalho utilizou de uma metodologia computacional, através de simulação Monte Carlo com o código PENELOPE. Foram simulados feixes clínicos de 50, 80, 150 e 250 kVp, Ir-192 e 6 MV, e um modelo de célula tumoral com AuNPs incorporadas com diferentes concentrações de ouro. $\mathrm{O}$ modelo de células utilizado possui $13 \mu \mathrm{m}$ de diâmetro externo máximo e 2 $\mu \mathrm{m}$ de diâmetro no núcleo. Dois modelos de incorporação de AuNPs foram implementados: modelo homogêneo e modelo heterogêneo. No modelo homogêneo, as AuNP foram distribuídas homogeneamente no núcleo e as células foram irradiadas nas diferentes energias estudadas para avaliar o fator de aumento de dose (DEF) em função da concentração de ouro na célula e da energia do feixe. No modelo heterogêneo, aglomerados de AuNPs foram simulados individualmente dentro da célula. Neste modelo foram utilizados somente os espetros de radiação que apresentaram os melhores desempenhos no modelo homogêneo. Foram avaliadas a fluência de partículas ejetadas nas AuNPs, o DEF, as distribuições de doses e os perfis de dose com aglomerados de 50 a $220 \mathrm{~nm}$ na célula. Os resultados obtidos para o modelo homogêneo mostram que os feixes de baixa energia são os que proporcionam maior DEF para uma mesma concentração de AuNP. Os maiores DEFs obtidos foram de 2,80; 2,99; 1,62 e 1,61, para os feixes de $50 \mathrm{kVp}, 80 \mathrm{kVp}, 150 \mathrm{kVp}, 250 \mathrm{kVp}$, respectivamente, sendo a maior incerteza de $1,9 \%$ para o feixe de $250 \mathrm{kVp}$. Através dos resultados obtidos com o modelo heterogêneo foi possível concluir que os elétrons ejetados possuem maior influência no aumento local da dose. Os perfis de dose, extraídos das distribuições de doses, para os aglomerados simulados permitiram obter os alcances das isodoses de 50, 20 e $10 \%$ da dose no entorno das AuNPs. Através desses perfis de dose pode-se concluir que o aumento de dose é local, da ordem de alguns micrômetros, dependendo do tamanho das nanopartículas e da energia do feixe primário. Para o feixe de $50 \mathrm{kVp}$, o DEF encontrado para uma incorporação heterogênea de seis aglomerados de AuNPs, correspondendo a um modelo clínico real, foi de 1,79 , com incerteza de $0,4 \%$. Com base nos resultados obtidos pode-se concluir que as energias de ortovoltagem proporcionam maior fator de aumento de dose que feixes de megavoltagem utilizados em teleterapia convencional. Além disso, o reforço local de dose pode proporcionar um fator de radiossensibilização celular se as AuNPs forem incorporadas no núcleo das células, nas redondezas do DNA, proporcionando um maior potencial de controle tumoral.

Palavras-chave: Radioterapia, nanopartícula de ouro, fator de aumento de dose, simulação Monte Carlo. 


\begin{abstract}
Santos, Vinícius Fernando dos. Dose enhancement factor in radiation therapy with nanoparticles: a Monte Carlo simulation study. 2017. Dissertation (Master degree) Department of Physics, Faculty of Philosophy, Sciences and Letters at Ribeirão Preto, University of São Paulo, Ribeirão Preto, 2017.
\end{abstract}

The incorporation of metal nanoparticles into tumor tissues has been studied in radiation therapy given of the dose enhancement that can be obtained in the target volume of the treatment. Studies indicate that gold nanoparticles (AuNP) are among the highest biologically viable for such applications, due to their low toxic potential. In addition, studies show that AuNP from a few nanometers to a few micrometers can permeate blood vessels that feed tumors, allowing their incorporation into tumor cells. Hence, this study's goal was to study the dose enhancement factors obtained in radiation therapy with AuNP incorporated in the tumor using orthovoltage, brachytherapy and teletherapy beams. This work used a computational methodology, through Monte Carlo simulation with the PENELOPE package. Clinical beams of 50, 80,150 and $250 \mathrm{kVp}, \mathrm{Ir}-192$ and $6 \mathrm{MV}$ were simulated with a tumor cell model with incorporated AuNPs. The cell model has maximum outer diameter of $13 \mu \mathrm{m}$ and $2 \mu \mathrm{m}$ of nucleus diameter. Two models of AuNP incorporation were implemented: homogeneous model and heterogeneous model. In the homogeneous model the AuNP were distributed homogeneously in the nucleus and the cells were irradiated in the different beams studied to evaluate the dose enhancement factors (DEF) as a function of concentration of gold in the cell and radiation beam. In the heterogeneous model, clusters of AuNPs were simulated individually within the cell. In this model, the radiation spectra used was selected among those that presented the best performances in the homogeneous model. The fluence of particles ejected from the AuNPs, the DEFs, the dose distributions and dose profiles for clusters of 50 to $220 \mathrm{~nm}$ in the cell were evaluated. The results obtained for the homogeneous model show that lower energy beams provide the highest DEFs for the same concentration of AuNP. The highest DEFs obtained were 2.80; 2.99; 1.62 and 1.61 , for the beams of $50 \mathrm{kVp}, 80 \mathrm{kVp}, 150$ $\mathrm{kVp}, 250 \mathrm{kVp}$, respectively, with a maximun uncertainty of $1.9 \%$ for the $250 \mathrm{kVp}$ beam. Through the results obtained with the heterogeneous model it was possible to conclude that the electrons ejected from he AuNPs have the major influence on the local dose enhancement. The dose profiles extracted from the dose distributions for the simulated clusters allowed the evaluation of the ranges for the 50, 20 and 10\% isodoses in the surroundings of the AuNPs. Through these dose profiles, it can be concluded that the dose increase is local, in the order of a few micrometers, depending on the size of the nanoparticles and the energy of the primary beam. For the $50 \mathrm{kVp}$ beam, the DEF found for a heterogeneous incorporation of six clusters of AuNPs, corresponding to an actual clinical model, was 1.79 , with uncertainty of $0.4 \%$. Based on the results obtained it can be concluded that kilovoltage energies provide a higher dose enhancement factor than megavoltage beams used in teletherapy. In addition, local dose enhancement may provide a cellular radiosensitization factor if the nanoparticles are incorporated in the nucleus of the cells, in the vicinity of the DNA, providing an enhanced potential for tumor control.

Key words: Radiotherapy, gold nanoparticle, dose enhancement factor, Monte Carlo simulation. 


\section{Lista de Figuras}

Figura 1: Equipamento de acelerador linear, comumente utilizado em teleterapia (obtido em: $\quad$ https://www.varian.com/oncology/products/treatment-delivery/truebeamradiotherapy-system ) 5

Figura 2: (a) Equipamento de braquiterapia remota e (b) exemplo de posicionamento utilizado na técnica de braquiterapia (obtido em: https://www.elekta.com/brachytherapy/microselectron-digital-treatment-delivery/\#) ... 6

Figura 3: Aparelho típico de Ortovoltagem com energias da ordem quilovoltagem. (Obtido em: http://www.medicalexpo.com/prod/xstrahl/product-75120-558495.html) .. 6

Figura 4: Imagem de microscopia eletrônica de transmissão de célula com distribuições in vivo e tamanhos reais de AuNPs: escala da figura de $100 \mathrm{~nm}$ (a) e $2 \mu \mathrm{m}$ (b) (Marques, 2013).

Figura 5: Intervalos de predominância dos efeitos de interação para diferentes números atômicos do atenuador e energias do feixe (Adaptado de Attix, 2004).

Figura 6: Ilustração do efeito fotoelétrico (Adaptado de Khan e Gibbons,2014). 12

Figura 7: Ilustração efeito Compton (Adaptado de Khan e Gibbons,2014). 13

Figura 8: Processo de produção de pares (Khan e Gibbons,2014). 14

Figura 9: Modelo de geometria construída no PENELOPE para representação de um objeto simulador com diversos materiais.

Figura 10: Espectro de energia do feixe utilizado: $50 \mathrm{kVp}$ (Rosenschold et al, 2008). . 19

Figura 11: Espectro de energia do feixe utilizado de $80 \mathrm{kVp}$ (Rosenschold et al, 2008).

Figura 12: Espectro de energia do feixe utilizado de $150 \mathrm{kVp}$ (Brown, S. et al, 2011). 20

Figura 13: Espectro de energia do feixe utilizado de $250 \mathrm{kVp}$ (Rosenschold et al, 2008).

Figura 14: Espectro de energia do feixe utilizado de 192Ir (Zilio, V. O. et al, 2004).... 21

Figura 15: Espectro de energia do feixe utilizado de 6 MV (Sheikh-Bagheri e Rogers, 2002). 
Figura 16: Modelo de célula utilizado nas simulações computacionais (Adaptada de Douglass et al, 2012).

Figura 17: Modelo de célula com incorporação homogênea de ouro no núcleo da célula, para as diferentes concentrações utilizadas na simulação. A cor verde representam a estrutura celular, preenchida com água na simulação, e a região magenta representa o núcleo da célula preenchida com diferentes concentrações de ouro de forma homogênea.

Figura 18: Modelo de célula com nanopartícula de $220 \mathrm{~nm}$ incorporada no núcleo. As diferentes cores representam as estruturas celulares, que foram preenchidas com água na simulação, e a região magenta representa a nanopartícula. 27

Figura 19: Representação do modelo de incorporação heterogênea de aglomerados de AuNPs na célula. As diferentes cores representam as estruturas celulares, que foram preenchidas com água na simulação, e os pontos coloridos no núcleo representa os diferentes tamanhos de nanopartículas. 30

Figura 20: Fatores de aumento de dose em função das concentrações de AuNPs e dos feixes clínicos simulados.

Figura 21: Fótons que entram e saem das AuNPs para o feixe de $50 \mathrm{kVp}$. 36

Figura 22: Elétrons que entram e saem das AuNPs para o feixe de $50 \mathrm{kVp}$. 37

Figura 23: Fótons que entram e saem das AuNPs para o feixe de $150 \mathrm{kVp}$.

Figura 24: Elétrons que entram e saem da AuNP para o feixe de $150 \mathrm{kVp}$. 38

Figura 25: Fótons que entram e saem das AuNPs para o feixe de ${ }^{192} \mathrm{Ir}$. 38

Figura 26: Elétrons que entram e saem da AuNP para o feixe de ${ }^{192}$ Ir. 39

Figura 27: Distribuição de doses para uma única AuNP incorporada e feixe de $50 \mathrm{kVp}$ : (a) $50 \mathrm{~nm}$, (b) $100 \mathrm{~nm}$ e (c) $220 \mathrm{~nm}$.

Figura 28: Distribuição de doses para uma única AuNP incorporada e feixe de $150 \mathrm{kVp}$ : (a) $50 \mathrm{~nm}$, (b) $100 \mathrm{~nm}$ e (c) $220 \mathrm{~nm}$.

Figura 29: Distribuição de doses para uma única AuNP incorporada e feixe de ${ }^{192}$ Ir: (a) $50 \mathrm{~nm}$, (b) $100 \mathrm{~nm}$ e (c) $220 \mathrm{~nm}$. 
Figura 30: Fatores de aumento de dose em função dos tamanhos dos aglomerados de AuNPs e dos feixes clínicos simulados.

Figura 31: Perfis de doses para modelo heterogêneo com AuNP única e feixe de 50 kVp: (a) $50 \mathrm{~nm}$, (b) $100 \mathrm{~nm}$ e (c) $220 \mathrm{~nm}$....

Figura 32: Perfis de doses para modelo heterogêneo com AuNP única e feixe de 150

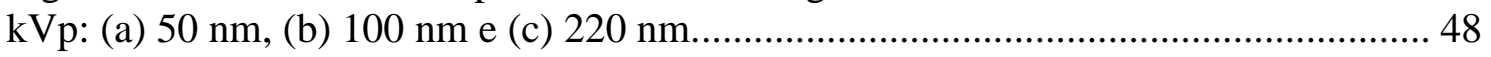

Figura 33: Perfis de doses para modelo heterogêneo com AuNP única e feixe de ${ }^{192}$ Ir: (a) $100 \mathrm{~nm}$ e (b) $220 \mathrm{~nm}$.

Figura 34: Distribuição de doses para célula com diferentes tamanhos de aglomerados de AuNPs no núcleo e irradiada com feixe de $50 \mathrm{kVp}$ 


\section{Lista de Tabelas}

Tabela 1: Parâmetros e valores utilizados nas simulações. 18

Tabela 2: Energias de feixe e concentrações de AuNPs utilizadas nas simulações do modelo homogêneo.

Tabela 3: Fatores de aumento de dose para as concentrações de ouro e feixes estudados. 34

Tabela 4: Fator de aumento de dose para os feixes e diferentes tamanhos de AuNP estudados no modelo heterogêneo. 46

Tabela 5: Alcance das isodoses em torno das AuNPs no modelo homogêneo com nanopartícula única. 


\section{Sumário}

Resumo

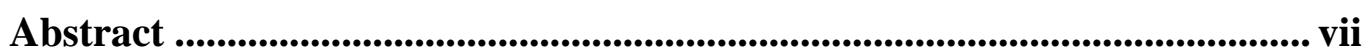

Lista de Figuras................................................................................................. viii

Lista de Tabelas .............................................................................................. $\times 1$

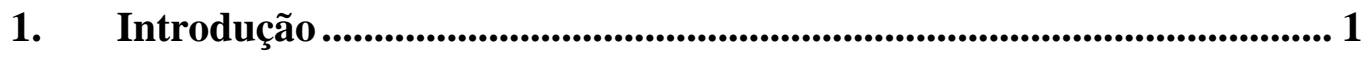

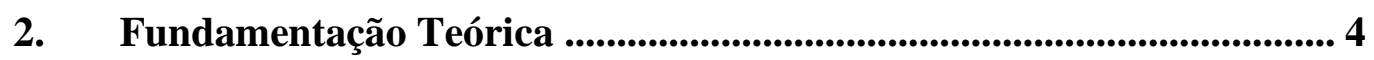

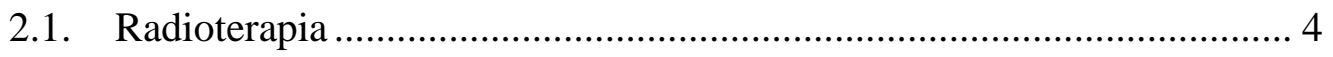

2.2. Radioterapia com nanopartículas ...................................................... 7

2.2.1. Modelo de incorporação in vivo de AuNPs .................................... 8

2.2.2. Fator de aumento de dose (DEF) ............................................ 9

2.3. Interações da radiação eletromagnética com a matéria nas energias de

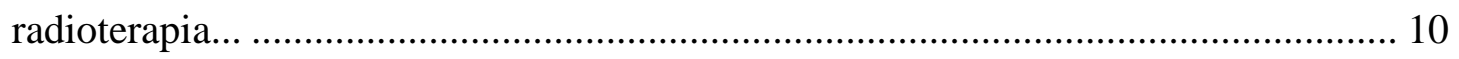

2.3.1. Efeito Fotoelétrico .................................................................... 11

2.3.2. Efeito Compton..................................................................... 12

2.3.3. Produção de Pares.......................................................................... 14

2.4. Simulação Monte Carlo com o pacote PENELOPE ............................. 15

3. Materiais e métodos.................................................................... 18

3.1. Simulação Monte Carlo com o pacote PENELOPE .............................. 18

3.2. Feixes de radiação ........................................................................... 19

3.3. Geometria: nanopartículas e modelo de célula ................................. 22

3.4. Modelos de incorporação de AuNPs nas células ................................. 23

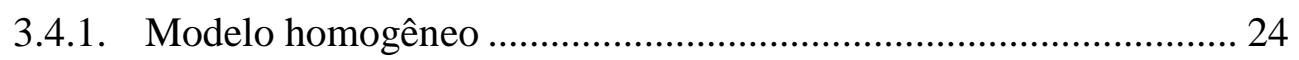

3.4.2. Modelo heterogêneo ............................................................... 26

3.4.2.1. Modelo heterogêneo com uma AuNP internalizada .............. 27

3.4.2.2. Modelo heterogêneo com vários aglomerados de AuNPs incorporados 30

4. Resultados e discussões 
4.1. Modelo homogêneo

4.2. Modelo Heterogêneo 35

4.2.1. Modelo heterogêneo com uma AuNP incorporada 35

4.2.1.1. Fluência de radiação ejetada pelas AuNPs 35

4.2.1.2. Distribuição de doses e DEF 41

4.2.1.3. Perfis de doses.................................................................. 46

4.2.2. Modelo heterogeneo com vários clusters de Nanopartículas 52

5. Conclusões 54

6. Referências Bibliográficas 55 


\section{Introdução}

Logo após a descoberta dos raios X, por Röntgen, em 1895, e da radioatividade, por Becquerel, em 1896, teve início o uso desenfreado das radiações ionizantes em pesquisas e estudos (Dutreix, 1995). Na medicina, o uso da radiação vem sendo pesquisado nas áreas de Radioterapia, Medicina Nuclear e Radiodiagnóstico (Pianoschi, 2008), também com interesse nos danos biológicos causado por sua interação no meio celular, que pode dar origem a um dano tardio no corpo do paciente dependendo do tipo e da dose de radiação utilizada. A Radioterapia envolve o uso de radiações de alta energia, como raios-x e raios gama, para destruir células tumorais e, inevitavelmente, causando efeitos deletérios para tecidos saudáveis ao longo do caminho de radiação (Sung, et al, 2016).

Com as deficiências em algumas modalidades atuais de tratamento para o câncer, um impulso crítico para melhorar a terapia do câncer é direcionar especificamente os agentes terapêuticos para as células tumorais, evitando que os tecidos saudáveis sejam prejudicados. Este é um dos interesses emergentes na pesquisa em nanotecnologia aplicada à Saúde. A rápida expansão na pesquisa de nanomateriais aumenta a perspectiva futura de novos métodos de diagnóstico e tratamento de doenças. Este ramo da nanotecnologia no diagnóstico, monitoramento e tratamento de doenças tem sido denominado "nanomedicina" pelo Instituto Nacional de Saúde nos EUA (Webster, 2006).

O uso das nanopartículas em medicina vem sendo extensamente estudado, com aplicações potenciais em terapia para câncer, doenças inflamatórias, imunoterapia para diversas doenças, hipertemia e outras (Haque, F et al, 2017; Her, et al, 2017; Li, et al, 2017; Lee, et al, 2017; Dearling e Packard, 2017; Grabbe, et al, 2016; Sung, et al, 2016; Wilhelm et al, 2016; Kubischok, 2015; Jain, 2015; Hao, et al, 2015; Kapadia, et al, 2015; Daehring, et al, 2015; Hauser, et al, 2015).

Um dos principais desafios nessas aplicações é a escolha dos carreadores adequados para que as nanopartículas sejam incorporadas apenas nos tecidos desejados (Li, et al, 2017; Yurkin, et al, 2017; Barua e Mitragotri, 2014; Nichols e Bae, 2012). Para o caso de tecidos tumorais, entretanto, a vascularização desordenada e porosa produzida pelo processo de angiogênese tumoral confere alta permeabilidade das 
nanopartículas ao tecido, dando origem ao chamado efeito de permeabilidade e retenção. Desta forma, para o tumor, a incorporação das nanopartículas é influenciada pelo grau de hipóxia das diferentes regiões do tumor, devido ao diferente grau de vascularização dessas regiões e do efeito de permeabilidade e retenção aumentada (EPR, do inglês Enhanced Permeability and Retention) (Wang, et al, 2016; Huynh, e Zheng, 2015; Kobayashi et al, 2014; Powathil, et al, 2012; Maeda, et al, 2000; Iyer, et al, 2000).

O tamanho, forma e composição da nanopartícula tem uma importância fundamental na sua cinética biológica, na sinalização celular desencadeada e na sua toxicidade (Stapletonet al, 2017; Tu, et al, 2017; Albanese, e Chan, 2012). A literatura mostra que nanopartículas de ouro (de tamanhos maiores que $5 \mathrm{~nm}$ ) apresentam menor toxicidade em relação a outros materiais, como a prata, por exemplo (Senguptaet al, 2014; Alkilany e Murphy, 2010).

Os primeiros estudos em Radioterapia com nanopartículas metálicas incorporadas assumia que o aumento potencial na resposta tumoral era devido a um aumento de dose devido ao aumento no número atômico efetivo do tecido, com conseqüente aumento na interação entre o tecido e a radiação, principalmente através do efeito fotoelétrico (Lechtmanet al, 2012; Chithrani, et al, 2010; Cho e Krishnan, 2007; Cho, 2005). Entretanto, a posição das nanopartículas no meio celular também pode ser responsável pelo aumento de radiossensibilização do tecido, contribuindo para a queda da sobrevivência celular (Sung, et al, 2017; Schuemannet al, 2016; Lechtmanet al, 2012; Chitrani, et al, 2010). Desta forma, estudos da potencialidade de Radioterapia com nanopartículas devem avaliar tanto o aumento de dose no volume tumoral quanto a radiossensibilização proporcionada pela distribuição das nanopartículas no meio celular.

O aumento de dose é regido por efeitos físicos de interação da radiação com o material, de forma que o espectro do feixe de radiação utilizado é de fundamental importância de modo a privilegiar efeitos de deposição de dose. Nesse sentido, o uso de feixes de radiação de energias como as utilizadas em ortovoltagem ou braquiterapia poderia ter uma vantagem potencial em relação aos feixes de teleterapia, que têm energias relativamente mais elevadas. Para avaliar essa hipótese, o conhecimento dos espectros de partículas secundárias liberadas pelas nanopartículas para o meio biológico é fundamental, já que o alcance de partículas secundárias está diretamente relacionado ao efeito local de aumento de dose. Já a avaliação da potencialidade sinergética do 
aumento de dose e da radiossensibilização pelas nanopartículas pode ser avaliado computacionalmente através da comparação do aumento de dose quando as nanopartículas são distribuídas em diferentes regiões do tecido tumoral.

Uma ferramenta eficaz para o estudo de fenômenos de atenuação da radiação e de deposição de dose em materiais são os códigos de simulação Monte Carlo, que representam uma alternativa conveniente em relação aos métodos experimentais, propiciando estudos detalhados em diferentes condições, de diversos processos que envolveriam muitos procedimentos experimentais (Seco e Verhaegen, 2013; Sempau et $a l .$, 1997). Dentre os códigos de simulação mais utilizado para simular a interação da radiação com a matéria, para aplicações em radiologia estão EGS4 (Bielajew e Rogers, 1992), MCNP (Hendrikcs et al, 2000) e, mais recentemente, GEANT4 (Alisson et al, 2006) e PENELOPE (Salvat et al, 2008).

Dessa forma, o objetivo geral deste trabalho foi avaliar o fator de aumento de dose em Radioterapia utilizando nanopartículas de ouro para diferentes feixes clínicos de tele e braquiterapia e ortovoltagem utilizando simulação Monte Carlo. Os objetivos específicos compreendem o estudo da fluência das partículas secundárias geradas dentro da nanopartícula e que são arremessados para fora do material contribuindo com o aumento local de dose, e ainda a avaliação da distribuição local das doses produzidas por nanopartículas de ouro incorporadas ao tecido tumoral.

No capítulo 2 é descrita toda a fundamentação teórica envolvida no trabalho. Neste capítulo são abordados os equipamentos e técnicas em radioterapia, os recentes desenvolvimentos do uso de nanopartículas em radioterapia, bem como detalhes do pacote de Simulação Monte Carlo PENELOPE.

No capítulo 3 deste trabalho são detalhados todos os materiais e métodos utilizados, como a simulação de Monte Carlo, espectros utilizados para as simulações, geometria e modelos de incorporação.

No capítulo 4 serão apresentados os resultados e discussões das análises realizadas para os diferentes modelos de incorporação das nanopartículas, por último, no capítulo 5 são apresentadas as conclusões do trabalho.

No capítulo 6 são apresentadas todas as referências bibliográficas que deram base para o desenvolvimento do trabalho. 


\section{Fundamentação Teórica}

Neste capítulo são apresentados os principais aspectos da Radioterapia, do uso de nanopartículas em Radioterapia e de simulação Monte Carlo com o código PENELOPE.

\subsection{Radioterapia}

A Radioterapia é uma das três principais modalidades terapêuticas utilizadas no tratamento de tumores, sendo as outras duas a cirurgia e a quimioterapia. A Radioterapia é uma modalidade de tratamento que utiliza radiação ionizante com a finalidade de destruir células tumorais com o menor dano possível em células sadias adjacentes (Salvajoli et al, 2013).

A aplicação das radiações ionizantes como tratamento tumoral teve início quando se notou que a radiação ionizante poderia danificar o material biológico, causando morte celular (Wagner et al, 1994). Após essa descoberta, os tratamentos começaram a ser realizados com equipamentos de raios- $\mathrm{X}$ e fontes radioativas, com os quais se conseguia destruir células tumorais. Entretanto, esses tratamentos também prejudicavam as células sadias adjacentes (André et al, 2011). Assim, com o tempo, surgiram diferentes equipamentos e técnicas de aplicações da radiação ionizante com o intuito de melhorar a conformação das doses aos volumes do tratamento. O uso e a indicação dessas técnicas radioterápicas, com os diferentes equipamentos e fontes de radiação, tem objetivo de aumentar a dose no tecido tumoral, buscando o aumento na probabilidade de controle tumoral (TCP, do inglês Tumor Control Probability) e a diminuição da probabilidade de complicação em tecidos normais (NTCP, do inglês Normal Tissue Complication Probability).

Em teleterapia, o paciente é posicionado à distância da fonte de radiação e o campo de radiação é aberto de forma a englobar o volume alvo do tratamento e poupar os tecidos sadios adjacentes. Os equipamentos mais utilizados em teleterapia são os aceleradores lineares, sendo possível gerar feixes de fótons e elétrons de alta energia $(\mathrm{MeV})$. Na Figura 1 é mostrado um acelerador linear típico, comumente utilizado em teleterapia. 


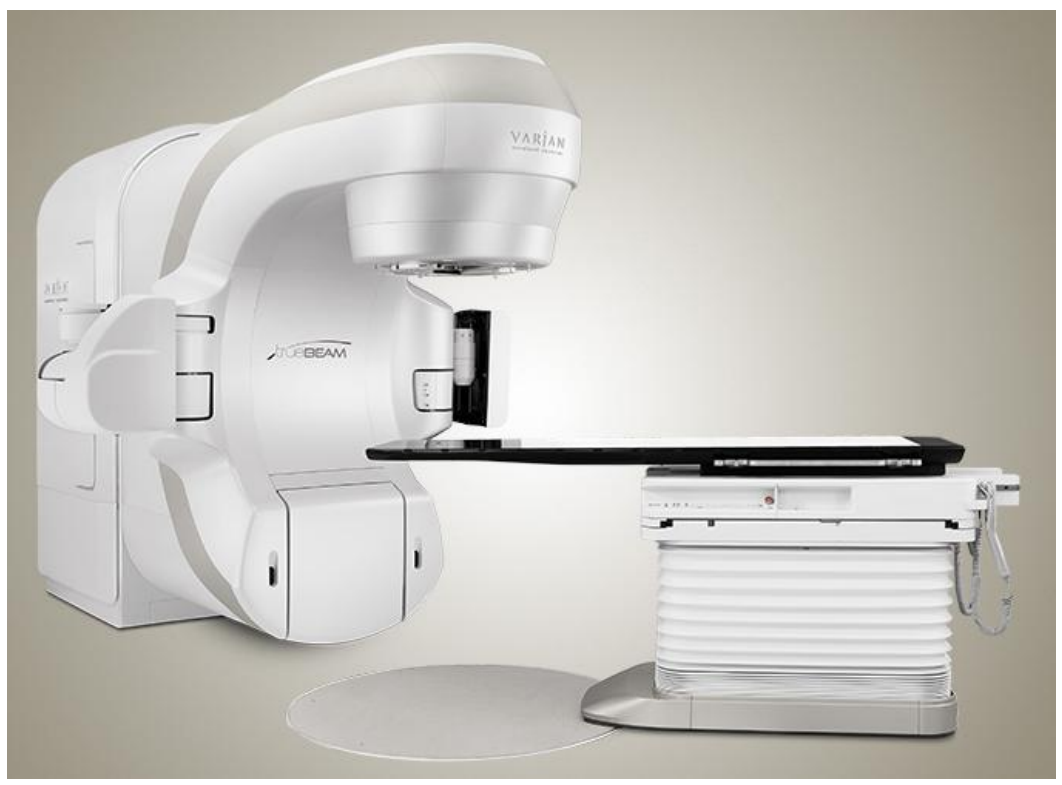

Figura 1: Equipamento de acelerador linear, comumente utilizado em teleterapia (obtido em: https://www.varian.com/oncology/products/treatment-delivery/truebeamradiotherapy-system )

A braquiterapia é uma modalidade de tratamento que utiliza fontes seladas em contato ou próximo ao tumor. O posicionamento das fontes é realizado, normalmente, através de um equipamento robótico capaz de levar a fonte até o local desejado para o tratamento. Com essa técnica são realizados tratamentos de altas taxas de dose (HDR, do inglês High Dose Rate), em que a fonte fica em contato com o tumor por um curto intervalo de tempo, ou de baixa taxa de dose (LDR, do inglês Low Dose Rate), em que a fonte permanece um intervalo de tempo relativamente longo em contato com o tumor. $\mathrm{Na}$ Figura 2 são mostrados um equipamento de braquiterapia HDR e um posicionamento utilizando a técnica de braquiterapia. 


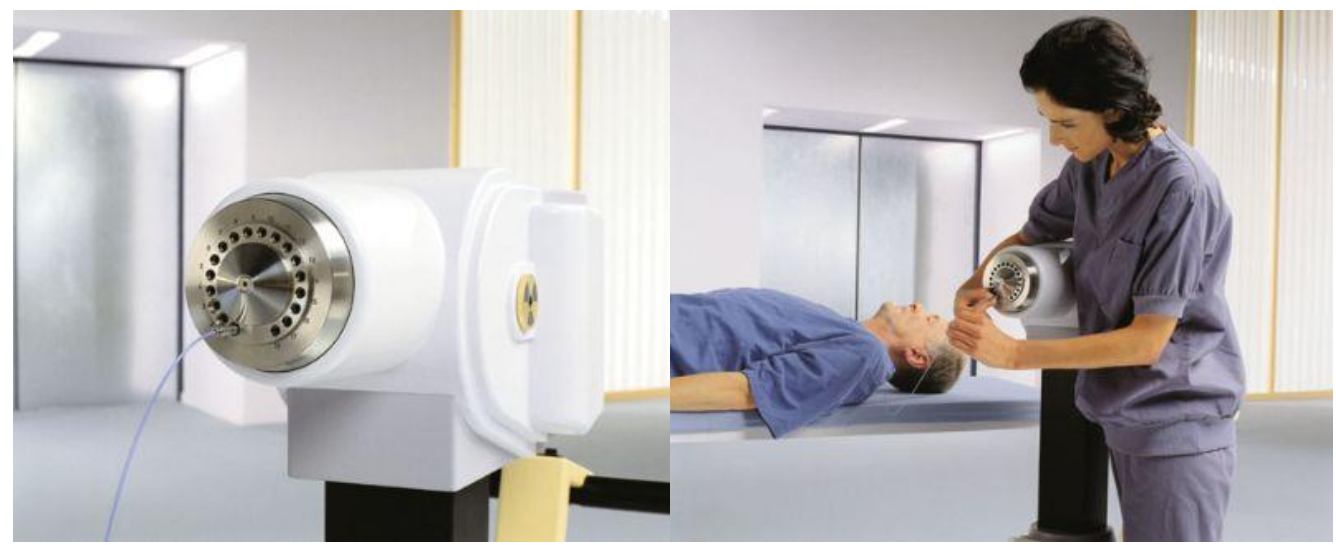

(a)

(b)

Figura 2: (a) Equipamento de braquiterapia remota e (b) exemplo de posicionamento utilizado na técnica de braquiterapia (obtido em:

https://www.elekta.com/brachytherapy/microselectron-digital-treatment-delivery/\#).

Equipamentos utilizando feixes de ortovoltagem são mais comumente utilizados em tratamentos superficiais por empregar feixes de fótons de baixas energias de radiação, na ordem de quiloelétrons-volt, que têm baixa penetração no tecido. Na Figura 3 são apresentados um aparelho típicos de ortovoltagem e um posicionamento típico nesses tratamentos.

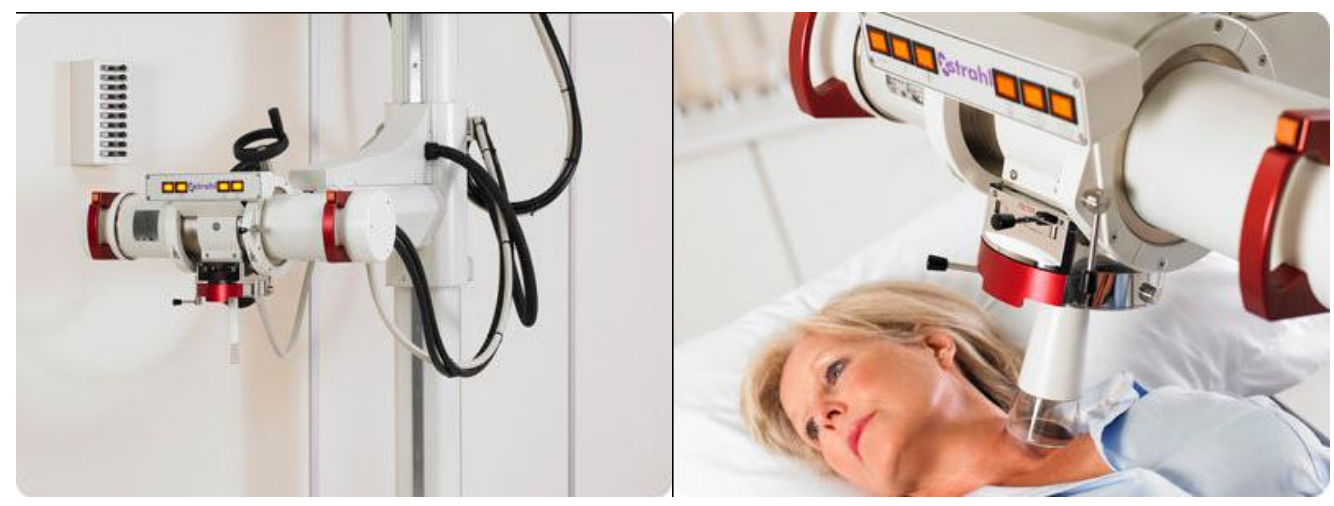

Figura 3: Aparelho típico de Ortovoltagem com energias da ordem quilovoltagem. (Obtido em: http://www.medicalexpo.com/prod/xstrahl/product-75120-558495.html) 
De forma geral, as técnicas e unidades de tratamento em radioterapia se desenvolveram para o aumento da exatidão e precisão do tratamento. Assim, os planejamentos baseados em imagens 3D possibilitaram a visualização e delimitação do volume alvo e dos órgãos de risco do tratamento, e, aliados a unidades de terapia com sistemas de colimação baseados em colimadores multi-folhas, permitiram aumentar a conformação das doses do tratamento. $\mathrm{O}$ desenvolvimento da radioterapia com feixe de intensidade modulada (IMRT do inglês Intensity Modulated Radiation Therapy), por sua vez, permitiu o escalonamento das doses no volume tumoral e a diminuição de efeitos colaterais dos tratamentos (Mundt e Roeske, 2005). Técnicas de IMRT em arco volumétrico (VMAT do inglês Volumetric Arc Therapy) têm, ainda, permitido uma melhor conformação da distribuição de doses e uma dose ainda menor no tecido sadio se comparada com IMRT (Otto, 2007).

Uma alternativa ao desenvolvimento tecnológico de unidades de terapia, para o aumento de doses no tumor, é a utilização de nanopartículas incorporadas ao volume tumoral. O uso de nanopartículas metálicas, pode auxiliar tanto no aumento quanto na conformação das doses em braquiterapia e em teleterapia (Schuemann et al, 2016).

\subsection{Radioterapia com nanopartículas}

O uso de nanopartículas metálicas em radioterapia foi baseado na idéia do aumento da probabilidade de interação entre feixes de radiação e materiais de alto número atômico. Estudos por simulação Monte Carlo mostraram que nanopartículas de ouro (AuNPs) proporcionam aumento das doses de radiação devido ao aumento de atenuação do feixe de radiação por processos de deposição de energia, como o efeito fotoelétrico (Lechtman, 2013; Cho, 2005). Os efeitos dosimétricos do aumento de dose das nanopartículas foram estudados tanto em contextos macroscópicos quanto microscópicos, mostrando que a produção de elétrons de baixas energias pelo material da nanopartícula produziam um aumento de dose no meio ao redor da mesma (Koger e Kirkby, 2016; Lechtman et al, 2013; Cho, 2005). Os primeiros estudos in vivo e in vitro da influência de AuNPs na sobrevivência celular foram realizados por Chitrani e colaborados, mostrando que seu uso pode proporcionar, além de aumento de dose, uma radiossensibilização tumoral, contribuindo para o aumento de resposta à radiação 
(Chitrani et al, 2010). A radiossensibilização celular depende, entretanto, do material, geometria e posição das nanopartículas no meio celular.

\subsubsection{Modelo de incorporação in vivo de AuNPs}

A incorporação in vivo de AuNPs no meio tumoral pode se dar a partir de processos passivos ou ativos. O processo passivo depende da permeabilidade alterada da vascularização tumoral para que as nanopartículas se incorporem no tumor, não dependendo da funcionalidade biológica das nanopartículas (Beddoes et al, 2015). Na incorporação ativa, as nanopartículas são funcionalizadas através de características físico-químicas de superfície que fazem com que o material tenda a se depositar em um tecido específico do corpo (Beddoes et al, 2015). Independentemente do mecanismo de incorporação, as nanopartículas tendem a se aglomerar no meio biológico formando aglomerados de diferentes diâmetros dentro das células.

A Figura 4 mostra a distribuição de aglomerados de AuNPs dentro de uma célula tumoral de próstata humana, em um modelo in vivo, obtida por Marques através de microscopia eletrônica de transmissão (Marques, 2013). Enquanto que as AuNPs administradas tinham diâmetro de $5 \mathrm{~nm}$, é possível observar que os aglomerados formados dentro da célula possuem, aproximadamente, 50 à $220 \mathrm{~nm}$. 

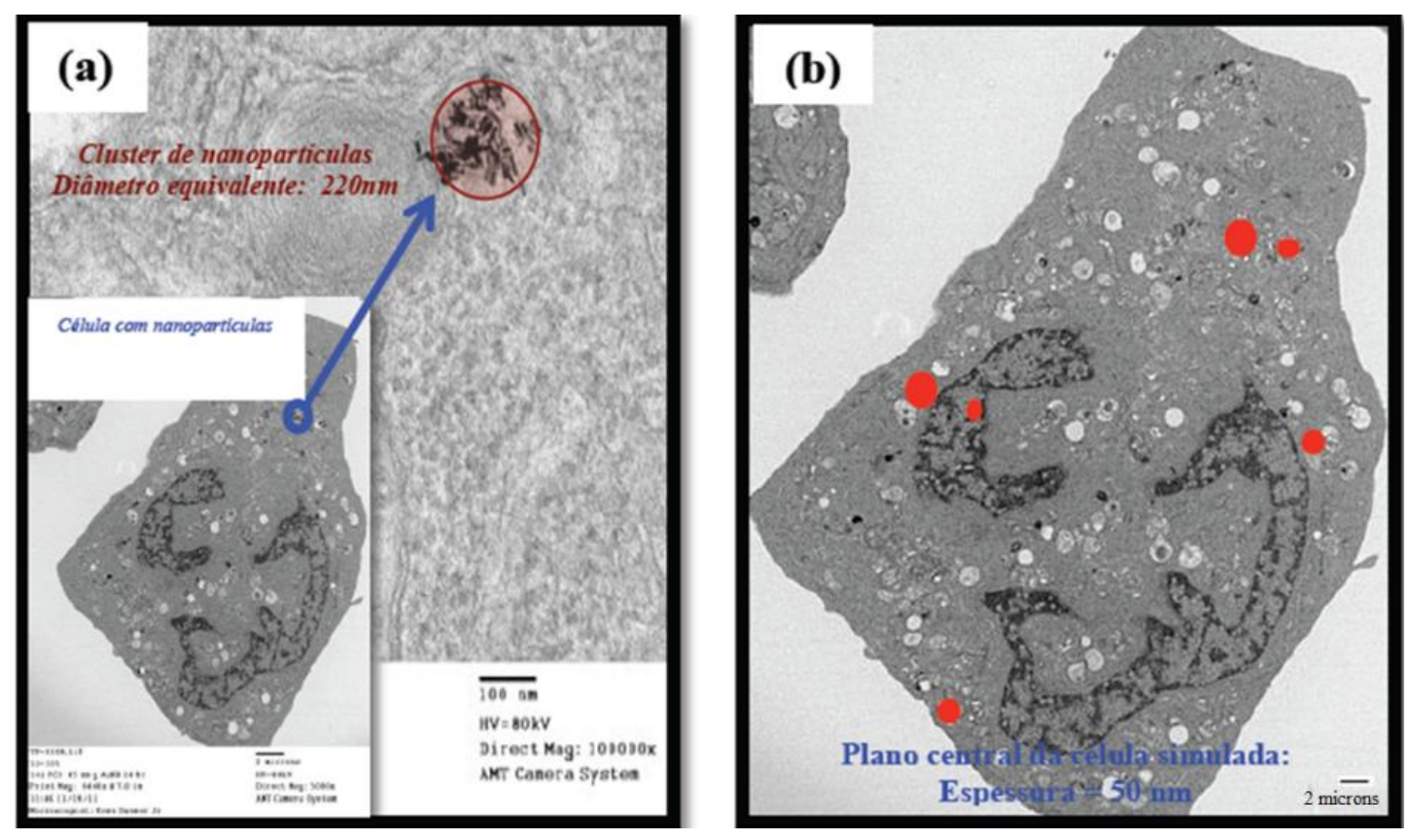

Figura 4: Imagem de microscopia eletrônica de transmissão de célula com distribuições in vivo e tamanhos reais de AuNPs: escala da figura de $100 \mathrm{~nm}$ (a) e $2 \mu \mathrm{m}$ (b) (Marques, 2013).

\subsubsection{Fator de aumento de dose (DEF)}

A partir da distribuição de AuNPs no meio biológico é possível determinar o fator de aumento de dose (DEF, do inglês Dose Enhancement Factor). O DEF é definido como a razão entre a dose total entregue ao volume biológico com nanopartículas incorporadas $\left(D_{c o m N P}\right)$ e a dose total integrada no mesmo volume sem a presença das nanopartículas $\left(D_{\text {semNP }}\right)$, sendo representado pela equação 1:

$$
D E F=\frac{D_{\text {comNP }}}{D_{\text {semNP }}}
$$

Em um modelo macroscópico, o DEF é considerado como consequência do aumento no número atômico efetivo do material pela incorporação da nanopartícula, sem consideração da fluência local de partículas secundárias no entorno da nanopartícula. Um modelo microscópico de análise do DEF, entretanto, mostra que os efeitos das nanopartículas são localizados no entorno das mesmas. Desta forma, o 
aumento de dose não é homogêneo em todo o volume biológico se a distribuição das nanopartículas não for homogênea. Do mesmo modo, a concentração de nanopartículas incorporadas ao volume influencia na atenuação da radiação secundária produzida no meio biológico: uma alta concentração de nanopartículas pode significar que parte da radiação secundária produzida por uma nanopartícula será absorvida por outra nanopartícula, e não pelo meio biológico adjacente, diminuindo, desta forma, o DEF. Assim, enquanto um modelo macroscópico de avaliação do DEF pode ser de fácil implementação e entendimento dosimétrico, a implementação de um modelo microscópico é fundamental para uma correta avaliação do DEF.

O estado atual do uso das nanopartículas em radioterapia passa pelo entendimento de como as nanopartículas podem potencializar a dose e a radiossensibilização, auxiliando no controle tumoral com uma diminuição dos efeitos colaterais. Uma vez que o potencial aumento de dose é dado pelo aumento na quantidade de elétrons secundários gerados a partir das interações da radiação com as nanopartículas, os efeitos de interações físicas da radiação com as nanopartículas devem ser estudados e compreendidos.

\subsection{Interações da radiação eletromagnética com a matéria nas energias de radioterapia}

A radiação eletromagnética incidente pode interagir de diferentes formas com a matéria, resultando em três tipos de efeitos predominantes na faixa de energias utilizadas em radioterapia, que são: efeito fotoelétrico, efeito Compton e a produção de pares. (Khan e Gibbons, 2014).

A importância relativa dos três principais efeitos de interação na faixa de energia de radioterapia depende da energia do fóton $(h v)$ e do número atômico $(Z)$ do material absorvedor. Na Figura 5 são apresentados os efeitos de interação predominantes para diferentes números atômicos do atenuador e energias do fóton incidente. 


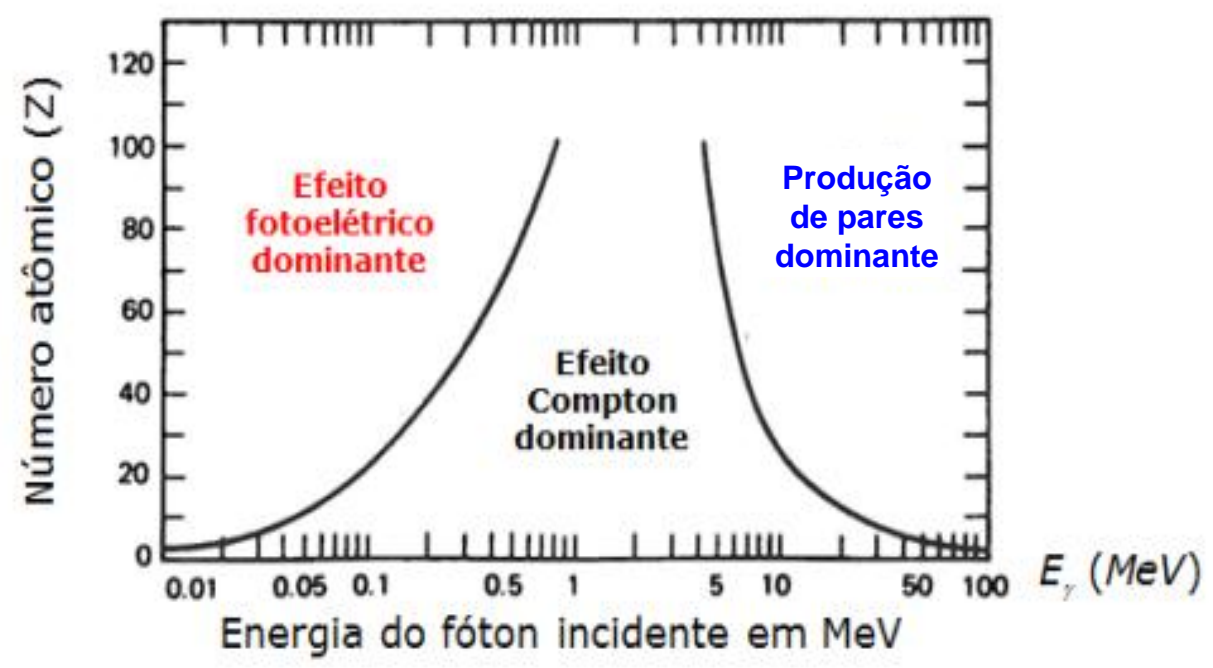

Figura 5: Intervalos de predominância dos efeitos de interação para diferentes números atômicos do atenuador e energias do feixe (Adaptado de Attix, 2004).

A partir da Figura 5 nota-se que o efeito fotoelétrico é dominante em baixas energias de fótons, o efeito Compton assume predominância nas energias intermediárias e produção de pares em energias altas, para materiais de variados números atômicos. Para baixos números atômicos (por exemplo, ar, água, tecido humano), a região de domínio do efeito Compton é bastante ampla, diminuindo gradualmente com o aumento de número atômico do atenuador. Para atenuadores de alto número atômico, a predominância do efeito fotoelétrico ocupa uma ampla faixa de energias para os feixes incidentes de baixa energia (Attix, 2004).

\subsubsection{Efeito Fotoelétrico}

O fenômeno do efeito fotoelétrico na interação da radiação com a matéria é considerado de grande importância em baixas energias e atenuadores de alto número atômico (Attix, 2004). Este efeito ocorre quando um fóton é completamente absorvido e, consequentemente, sua energia é totalmente transferida para um elétron fortemente ligado às camadas mais internas do átomo (camadas $\mathrm{K}, \mathrm{L}, \mathrm{M}$ e N). O átomo excitado ejeta um elétron orbital (fotoelétron) com a posterior emissão de raio-X característico. A interação do raio-X com outro elétron orbital pode dar origem à ejeção de um segundo 
elétron, chamado elétron Auger, de baixa energia e alto potencial de deposição de dose localmente. Na Figura 6 é apresentada uma ilustração do efeito fotoelétrico.

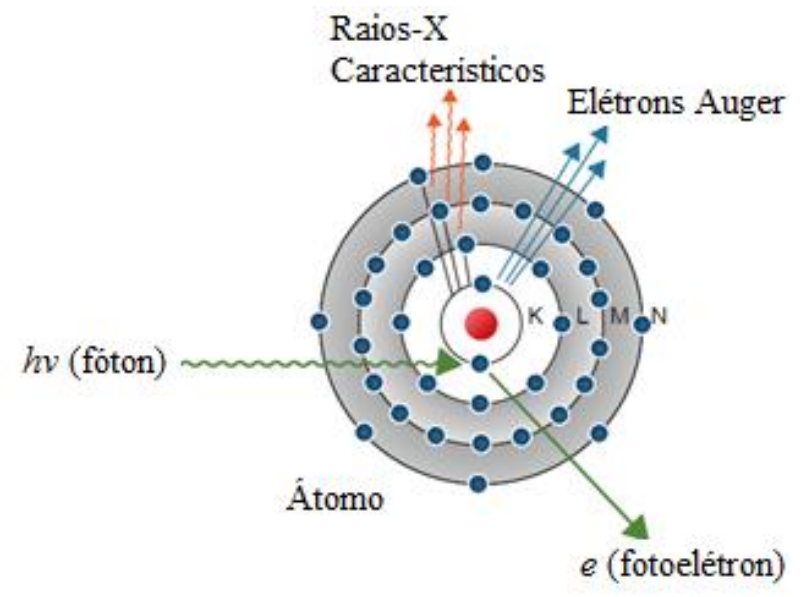

Figura 6: Ilustração do efeito fotoelétrico (Adaptado de Khan e Gibbons,2014).

Levando-se em consideração a lei de conservação de energia, a energia cinética do elétron ejetado pode ser descrita pela equação 2 :

$$
K_{e}=h v-E_{l}
$$

onde $K_{e}$ é a energia cinética do elétron ejetado, $h v$ é a energia do fóton incidente e $E_{l}$ é a energia de ligação da camada do átomo a que o elétron ejetado pertencia, chamada função trabalho do elétron. Desta forma, a produção do efeito fotoelétrico a partir de feixes de quilovoltagem produzirá fotoelétrons nessa mesma faixa de energia, que possuirão alcance de alguns micrômetros até alguns milímetros em materiais de número atômico próximo ao de tecidos biológicos, dependendo da combinação entre a energia do feixe e o número atômico do atenuador.

\subsubsection{Efeito Compton}

O espalhamento incoerente ou efeito Compton ocorre quando um fóton incidente $\left(h v_{0}\right)$ transfere parte de sua energia para um elétron das camadas mais externas do 
átomo. O elétron é ejetado de sua camada eletrônica e o fóton é espalhado com uma energia menor ( $\left.h v^{\prime}\right)$ que a energia inicial, como mostrado na Figura 7.

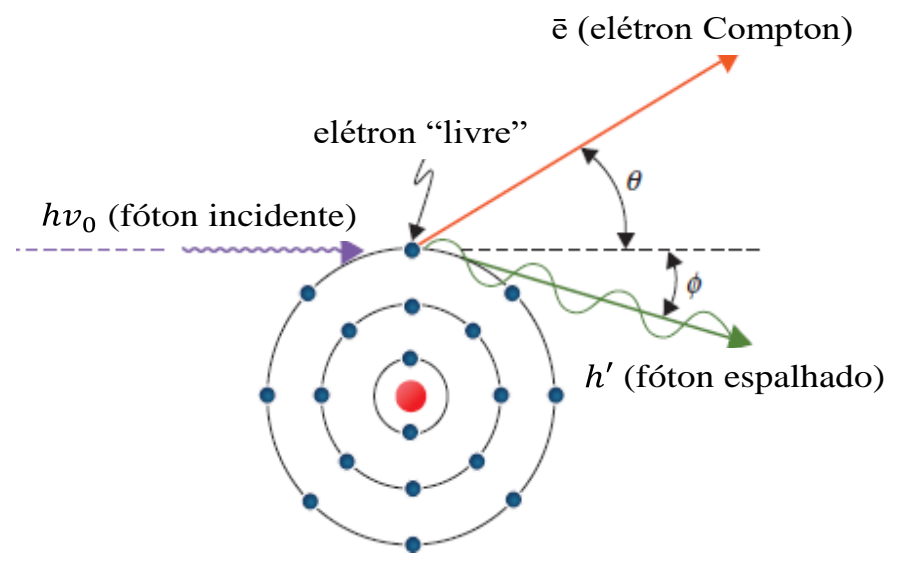

Figura 7: Ilustração efeito Compton (Adaptado de Khan e Gibbons,2014).

O processo Compton pode ser analisado em termos de uma colisão entre duas partículas, um fóton e um elétron, aplicando-se as leis de conservação do momento e da energia e obtendo-se as equações 3 e 4 para a energia do elétron e do fóton espalhado, respectivamente:

$$
\begin{gathered}
E=h v_{0} \frac{\alpha(1-\cos \phi)}{1+\alpha(1-\cos \phi)} \\
h v^{\prime}=\frac{h v_{0}}{1+\alpha(1-\cos \phi)}
\end{gathered}
$$

em que $h v_{o}, h v^{\prime}$ e E são as energias do fóton incidente, fóton espalhado e elétron, respectivamente, e $\theta$ e $\phi$ são os ângulos de espalhamento do elétron e do fóton, respectivamente (Khan e Gibbons, 2014; Attix, 2004). A produção do efeito Compton a partir de feixes de megavoltagem produzirá fotoelétrons nessa mesma faixa de energia, que possuirão alcance de milímetros até centímetros em materiais de número atômico próximo ao de tecidos biológicos, dependendo da combinação entre a energia do feixe e o número atômico do atenuador. 


\subsubsection{Produção de Pares}

No processo de produção de pares a energia do fóton incidente é convertida em massa de repouso e energia cinética de um par partícula-antipartícula (Okuno, 2010). Isto ocorre quando um fóton incidente é totalmente absorvido e possui uma energia maior que 1,022 MeV, gerando um par elétron-pósitron (Johns e Cunningham, 1983), como demonstrado na Figura 8.

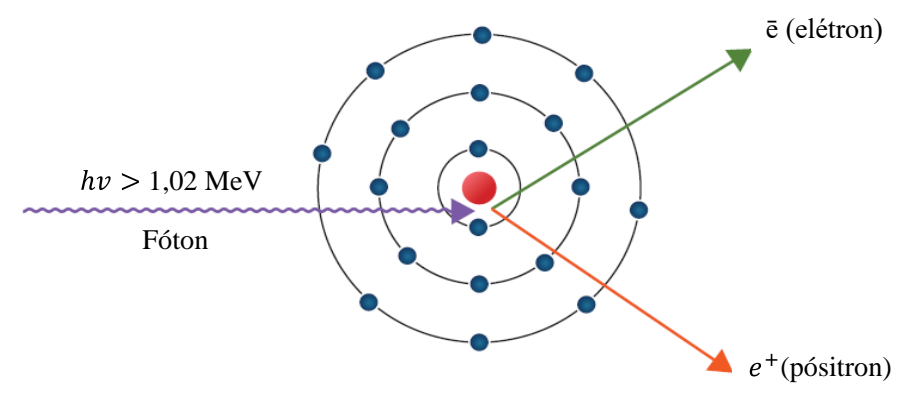

Figura 8: Processo de produção de pares (Khan e Gibbons,2014).

Assim, este efeito pode ser descrito, levando-se em consideração a conservação de energia, pela equação 5 .

$$
h v=2 m_{0} c^{2}+K^{-}+K^{+}
$$

sendo $m_{0} c^{2}=0,511 \mathrm{MeV}$ a energia de repouso de um elétron, $K$ energia cinética do elétron e $K^{+}$energia cinética do pósitron. Assim, a produção de pares por um feixe de magavoltagem irá conferir alcances típicos ao elétron e ao pósitron de alguns centímetros em meios de número atômico próximo ao de tecidos biológicos (Attix, 2004).

A simulação Monte Carlo é um método eficaz para análise da atenuação da radiação e das doses depositadas por feixes de radiação em materiais diversos, 
simulando as interações da radiação por meio de amostragens aleatórias que caracterizam o processo físico em uma geometria e material de interesse.

\subsection{Simulação Monte Carlo com o pacote PENELOPE}

O método de simulação Monte Carlo envolve a amostragem de uma função densidade de probabilidade de um dado fenômeno. Desta forma, o único requisito necessário para a utilização do método é que o processo físico em estudo possa ser descrito por funções de densidades de probabilidade (Yoriyaz, 2009).

Assim, qualquer simulação Monte Carlo é iniciada com a criação de um modelo que representa o sistema real de interesse. No caso da interação da radiação com a matéria, o modelo deve contemplar as características do feixe, dos materiais atenuadores e dos processos de interação. A partir do modelo construído, simulam-se interações sucessivas da radiação com o meio através de amostragens aleatórias das probabilidades de interação que caracterizam esses processos físicos (Yoriyaz, 2009).

Dentre os códigos de simulação existentes, os mais utilizados para simular a interação da radiação com a matéria, para aplicações em radiologia, são o EGS4 (Bielajew e Rogers, 1992), MCNP (Hendrikcs et al, 2000) e, mais recentemente, PENELOPE (Salvat et al, 2008) e GEANT (Alisson et al, 2006).

O pacote de simulação Monte Carlo PENELOPE (do inglês PENetration and Energy LOss of Positrons and Electrons) pode ser utilizado para simular o transporte de elétrons, pósitrons e fótons em uma geometria complexa. No pacote encontram-se várias subrotinas FORTRAN distribuídas em vários códigos fontes e organizadas em quatro códigos básicos: PENELOPE.f, contendo as subrotinas de transporte e interação das partículas; PENGEOM.f, contendo as subrotinas de geometria; PENVARED.f, contendo as subrotinas que executam os métodos de redução variacional e TIMER.f, que gerencia o tempo da simulação. O código ainda é distribuído com o código-fonte MATERIAL.f, que é responsável pela geração dos dados de seção de choque de cada material utilizado nas simulações.

Uma simulação com o pacote PENELOPE se inicia pela execução de um arquivo executável, que busca todas as informações do problema sendo simulado em 
arquivos de entrada fornecidos pelo usuário, além de informações da geometria e informações de seção de choque dos materiais envolvidos na simulação. O arquivo de entrada da simulação é um dos principais arquivos para a execução do código PENELOPE, e possui todas as informações sobre o campo de radiação, tipo e energia da partícula, parâmetros de controle da simulação, números de partículas a serem simuladas e tempo total de simulação, dentre outras informações pertinentes ao problema.

O algoritmo misto implementado no código PENELOPE permite que o usuário defina parâmetros de controle da simulação que são responsáveis tanto pela exatidão quanto pelo desempenho da simulação. Nesse tipo de algoritmo, o transporte de partículas carregadas pode ser detalhado, com a simulação de cada evento de interação individual, ou condensado, com a realização de eventos artificiais que agrupam uma série de interações fracas com o meio. Desta forma, enquanto que o transporte detalhado proporciona uma maior exatidão nas simulações, às custas de tempo computacional, o transporte condensado promove o aumento de desempenho das simulações às custas de exatidão dos resultados obtidos (Salvat, 2008).

A representação da geometria de simulação no pacote PENELOPE é realizada através de superfícies quadráticas e da definição de regiões no espaço em relação à essas superfícies. Volumes fechados correspondendo a regiões da geometria de simulação são definidos, desta forma, através da definição do espaço interno ou externo às intersecções dessas superfícies pré-definidas. Desta forma, o pacote permite a construção de geometrias complexas, constituídas por diversas regiões e materiais diferentes. A Figura 9 apresenta a visualização de uma geometria de um objeto simulador composto por diversos corpos e materiais e construída com PENELOPE. 


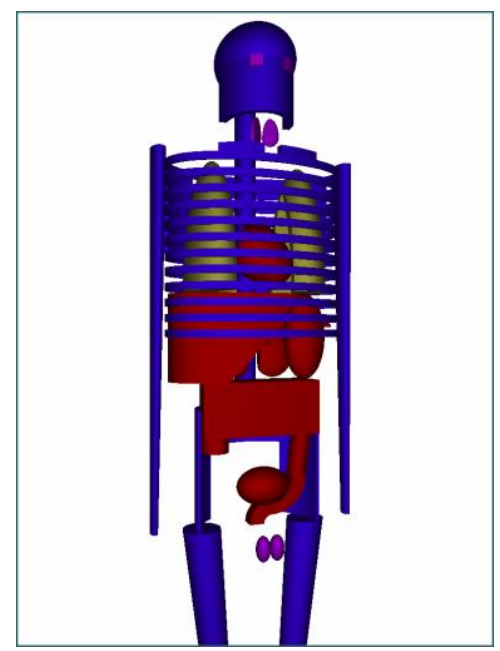

Figura 9: Modelo de geometria construída no PENELOPE para representação de um objeto simulador com diversos materiais.

Dentre as funcionalidades do pacote estão objetos para a subdivisão de regiões da geometria em elementos de volume (voxels) com resolução espacial definida pelo usuário. Essa funcionalidade é especialmente útil para a construção de distribuições de doses a partir das simulações. Outra funcionalidade do pacote é a possibilidade de obtenção das fluências de partículas que entram em um corpo qualquer definido na geometria de simulação. Ambas as funcionalidades podem ser utilizadas de acordo com parâmetros definidos pelo usuário no arquivo de entrada da simulação, facilitando análises dosimétricas e espectrométricas nas simulações realizadas. 


\section{Materiais e métodos}

Neste trabalho foi utilizada uma metodologia computacional, através de simulação Monte Carlo, para o estudo do fator de aumento de dose em Radioterapia utilizando nanopartículas de ouro incorporadas a uma célula tumoral.

\subsection{Simulação Monte Carlo com o pacote PENELOPE}

O pacote de simulação Monte Carlo PENELOPE, versão 2011, foi utilizado como ferramenta para representar os feixes clínicos de teleterapia, braquiterapia e ortovoltagem utilizados neste trabalho e para avaliar os DEFs, as distribuições de doses e as fluências produzidas pela incorporação de AuNPs em um modelo de célula.

As simulações foram realizadas em um cluster de 20 computadores do CeTI-RP - USP (Centro de Tecnologia da Informação de Ribeirão Preto - USP), sendo possível obter um melhor desempenho nas simulações em comparação com a realização de simulações em computadores pessoais. Os núcleos do cluster utilizado são compostos por processadores Intel i7 com 16 gigabytes de memória cada nó.

Todas as simulações realizadas neste trabalho utilizaram os parâmetros descritos na Tabela 1. Os parâmetros de controle da simulação (WCC e WCR) são específicos do código PENELOPE e controlam a condensação e/ou o detalhamento do transporte de partículas carregadas no algoritmo misto do código.

Tabela 1: Parâmetros e valores utilizados nas simulações.

\begin{tabular}{|c|c|}
\hline Parâmetro & Valor \\
\hline Partícula Primária & Fótons \\
\hline Parâmetros de controle da simulação & $\mathrm{C} 1$ e C2 $=0,05$ \\
& $\mathrm{WCC}$ e WCR $=10^{6} \mathrm{eV}$ \\
\hline Energias de corte & $10 \mathrm{keV}$ \\
\hline Número de partículas primárias & $8 \times 10^{11}$ \\
\hline
\end{tabular}




\subsection{Feixes de radiação}

Os espectros dos feixes polienergéticos utilizados nas simulações foram relativos a feixes clínicos de unidades de ortovoltagem, braquiterapia e teleterapia.

De acordo com a bibliografia, os feixes com energia de quilovoltagem podem proporcionar um alto DEF devido a alta probabilidade de gerar efeito fotoelétrico quando em combinação com um material de alto Z (Koger e Kirkby, 2016; Lechtman, et al, 2013; Jones, et al, 2010). Desta forma, feixes clínicos de 50, 80, 150 e $250 \mathrm{kVp}$ foram utilizados nas simulações correspondendo a feixes de ortovoltagem. O espectro de uma fonte de ${ }^{192} \mathrm{Ir}$, utilizada em Braquiterapia, foi também utillizado nas simulações dado que o uso essas fontes é bastante difundido e as energias intermediárias dessa fonte poderiam proporcionar altos DEFs. O feixe simulado de teleterapia, que foi estudado para comparação com as baixas energias utilizadas, foi um feixe de fótons de $6 \mathrm{MV}$ típico de um acelerador linear. A simulação desse feixe teve como objetivo determinar a sua relevância clínica em radioterapia com nanopartículas devido ao processo de interação predominante em materiais de alto número atômico e alta energia.

Os espectros dos feixes clínicos utilizados neste estudo são mostrados nas Figuras 10 a 15.

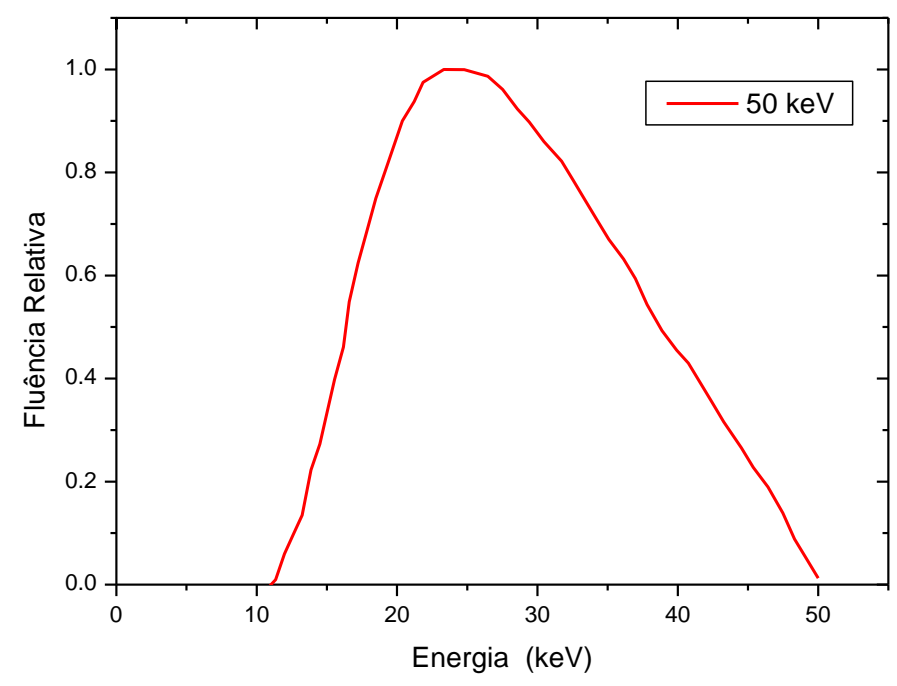

Figura 10: Espectro de energia do feixe utilizado: $50 \mathrm{kVp}$ (Rosenschold et al, 2008). 


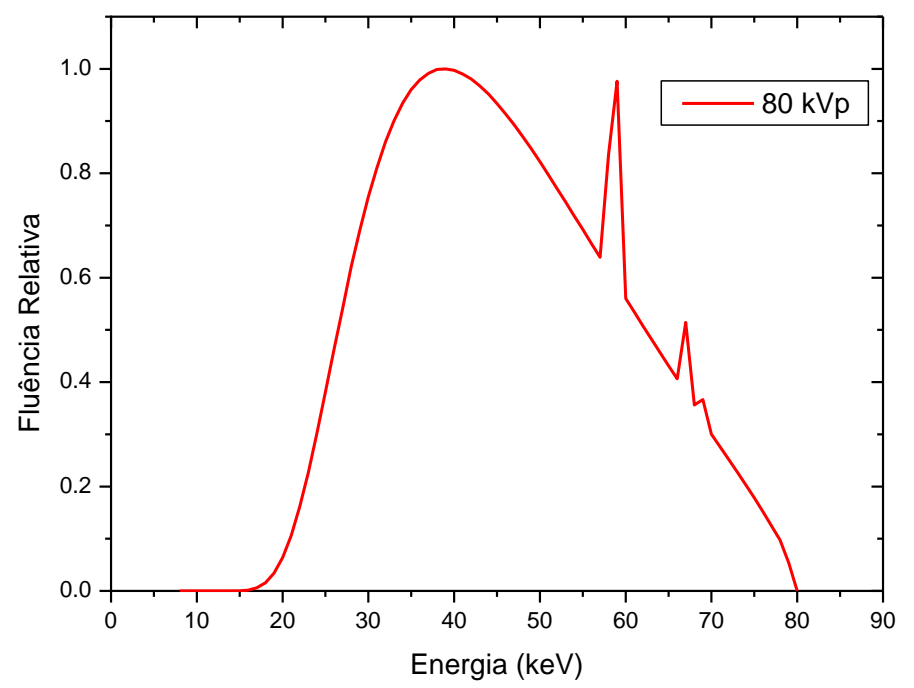

Figura 11: Espectro de energia do feixe utilizado de $80 \mathrm{kVp}$ (Rosenschold et al, 2008).

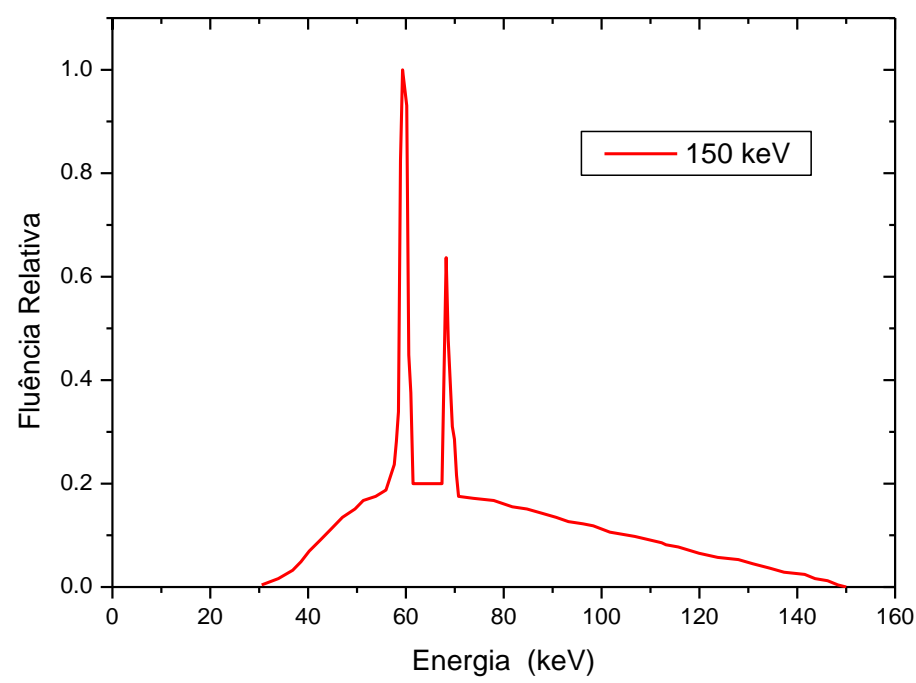

Figura 12: Espectro de energia do feixe utilizado de $150 \mathrm{kVp}$ (Brown, S. et al, 2011). 


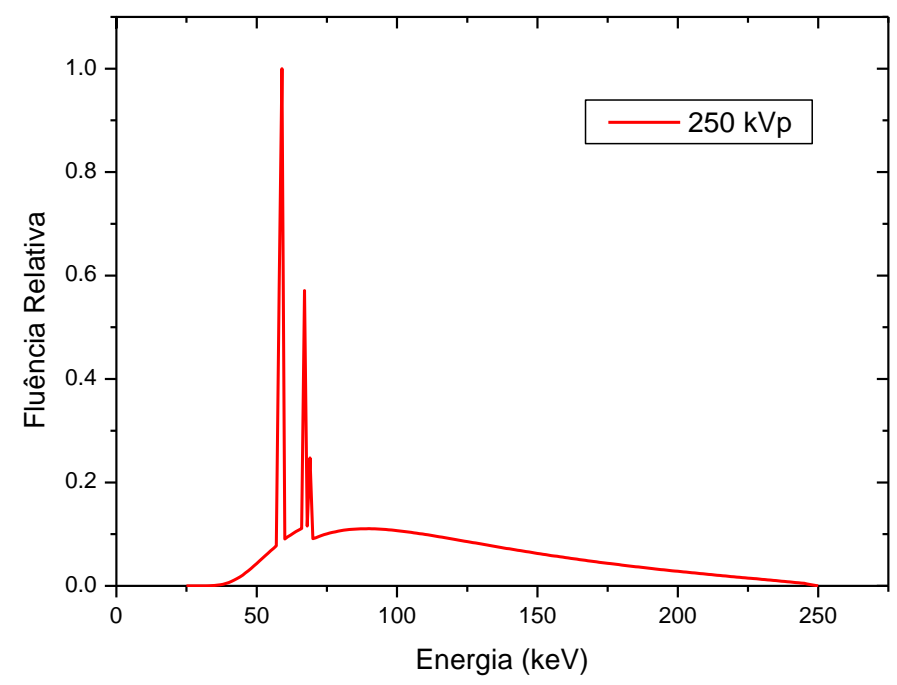

Figura 13: Espectro de energia do feixe utilizado de $250 \mathrm{kVp}$ (Rosenschold et al, 2008).

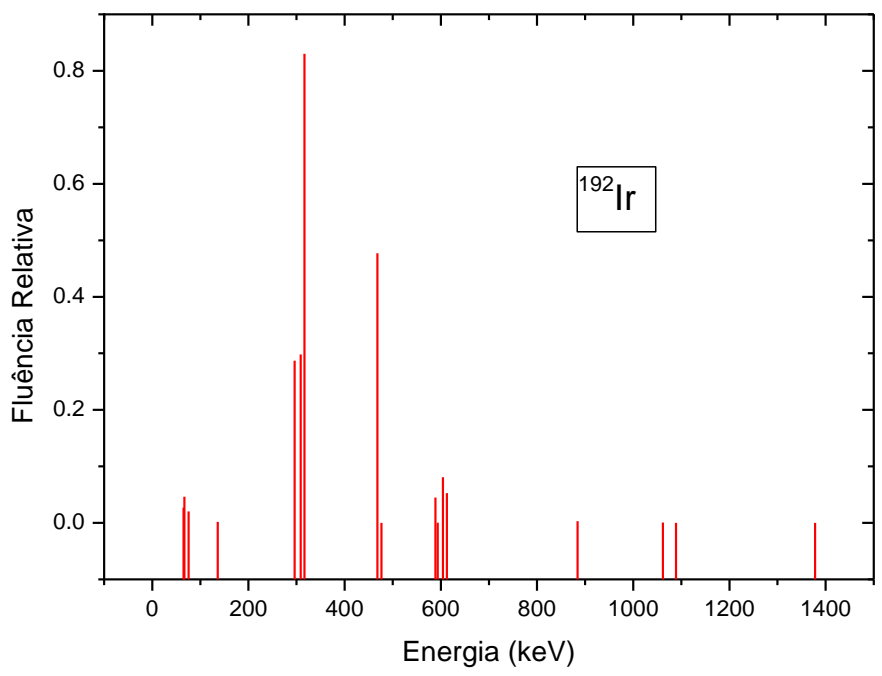

Figura 14: Espectro de energia do feixe utilizado de 192Ir (Zilio, V. O. et al, 2004). 


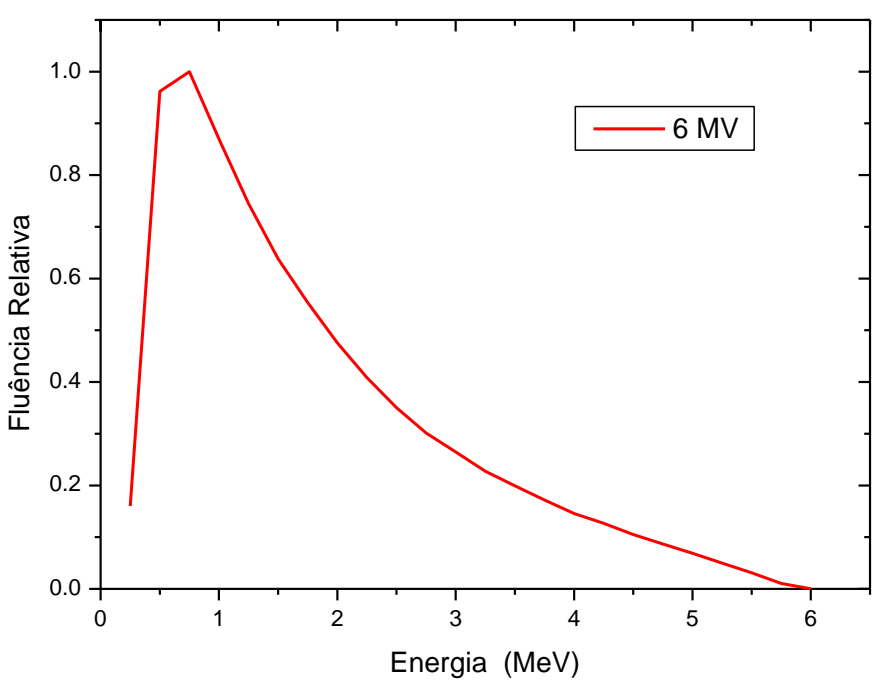

Figura 15: Espectro de energia do feixe utilizado de $6 \mathrm{MV}$ (Sheikh-Bagheri e Rogers, 2002).

\subsection{Geometria: nanopartículas e modelo de célula}

As nanopartículas consideradas neste trabalho foram compostas por ouro, em tamanhos que variaram de 50 à $220 \mathrm{~nm}$ quando considerados como aglomerados de nanopartículas para uma distribuição heterogênea dentro da célula, de acordo com trabalho in vivo de incorporação de AuNPs em células tumorais (Marques, 2013).

Para definição da geometria de célula no modelo computacional foi utilizado como referência o trabalho de Douglass e colaboradores, que utiliza simulação Monte Carlo e um modelo macroscópico de célula (Douglass et al, 2012). No modelo são usados tamanhos típicos reais das estruturas celulares, desde o núcleo até a membrana que reveste a célula, demonstrado na Figura 16. 


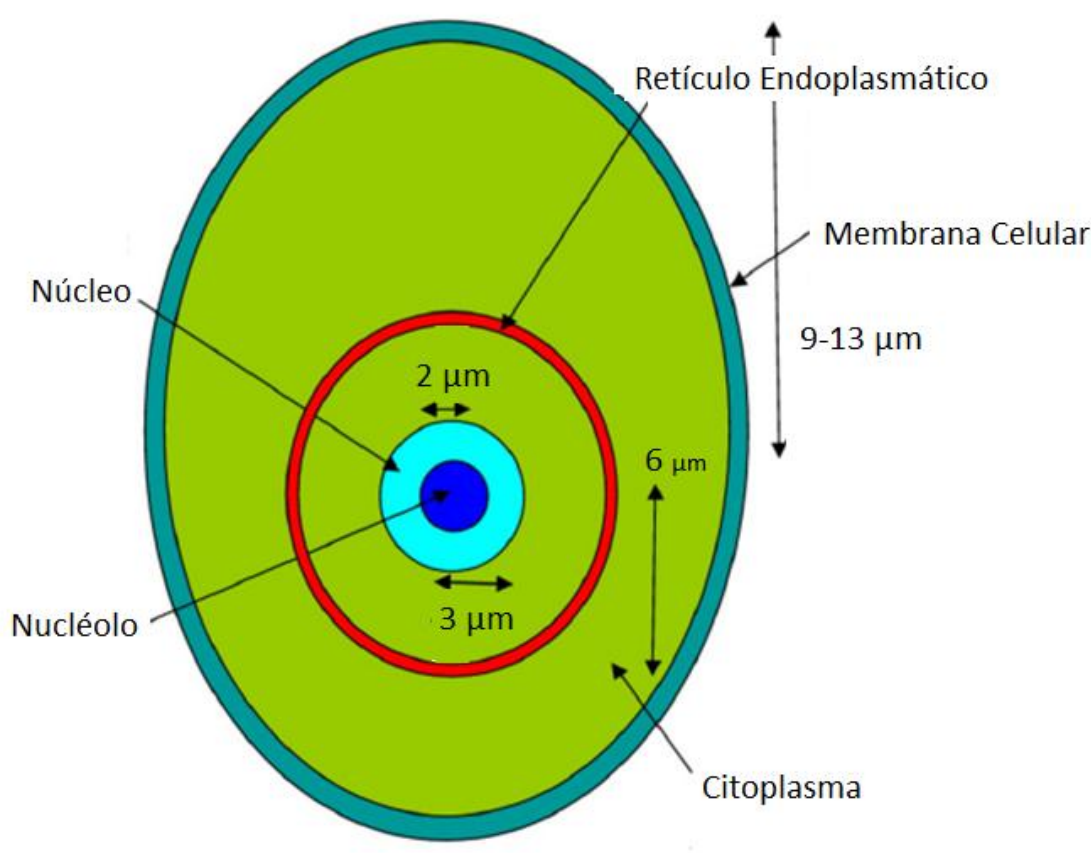

Figura 16: Modelo de célula utilizado nas simulações computacionais (Adaptada de Douglass et al, 2012).

\subsection{Modelos de incorporação de AuNPs nas células}

Neste trabalho foram considerados dois modelos de incorporação das nanopartículas nas células, sendo estes o modelo homogêneo e o modelo heterogêneo.

O modelo homogêneo consiste em uma mistura homogênea de ouro e água preenchendo o núcleo da célula. Nesse modelo, o número atômico efetivo do material homogêneo que forma o núcleo é função da concentração de ouro na mistura com a água. Essa distribuição homogênea de ouro não corresponde à incorporação in vivo, porém possibilita avaliar os DEFs macroscópicos em função da concentração das nanopartículas no meio e dos espectros de feixe utilizados.

O modelo heterogêneo considera a distribuição dos aglomerados de nanopartículas dispersos no meio biológico, ou seja, quando aglomerados são formados tendem a se distribuir de forma heterogênea na célula, em diferentes tamanhos. Neste trabalho, consideraram-se aglomerados esféricos de 50 a $220 \mathrm{~nm}$ dispersos em água, que representou o material biológico. 


\subsubsection{Modelo homogêneo}

O objetivo em preencher todo o núcleo da célula de forma homogênea com as misturas de diferentes concentrações de ouro é que um dos principais mecanismos de produção de morte celular é a irradiação do núcleo da célula. Desta forma, a vantagem do modelo homogêneo é a facilidade de determinação de um DEF macroscópico no núcleo da célula, calculado em todo o volume de incorporação das AuNPs, em função da concentração de nanopartículas e da energia do feixe.

Na implementação deste modelo assume-se que o ouro é homogeneamente incorporado no núcleo da célula, sem que a nanoestrutura do material seja considerada. Desta forma, o aumento de dose é consequência do aumento no número atômico efetivo do núcleo, sem consideração da influência local da fluência de partículas secundárias no entorno da nanopartícula e sem influência de interfaces entre as AuNPs e o material biológico.

O pacote PENELOPE foi utilizado para a geração de arquivos de materiais compostos por uma mistura homogênea de água e ouro, em concentrações de ouro de 0,$01 ; 0,05 ; 0,1 ; 0,5 ; 1,0$ e $1,1 \%$ em fração de peso. A escolha destas concentrações foi obtida com base em trabalhos anteriores (Chithrani, Jelveh, Jalali et al, 2010; Liu, Y., Liu, X. et al, 2015), que relatam que pequenas concentrações de nanopartículas apresentam uma maior facilidade de permeabilidade no meio celular, enquanto que maiores concentrações proporcionam maior potencial de radiossensibilização.

O código PENGEOM, do pacote PENELOPE, foi utilizado para a simulação de um objeto simulador representando uma célula única. $O$ volume representando o núcleo da célula foi preenchido com a mistura de água mais ouro, nas diversas concentrações estudadas, enquanto que o restante do objeto simulador foi preenchido com água. A Figura 17 apresenta uma representação da célula com o núcleo preenchido com a mistura de água mais ouro. 


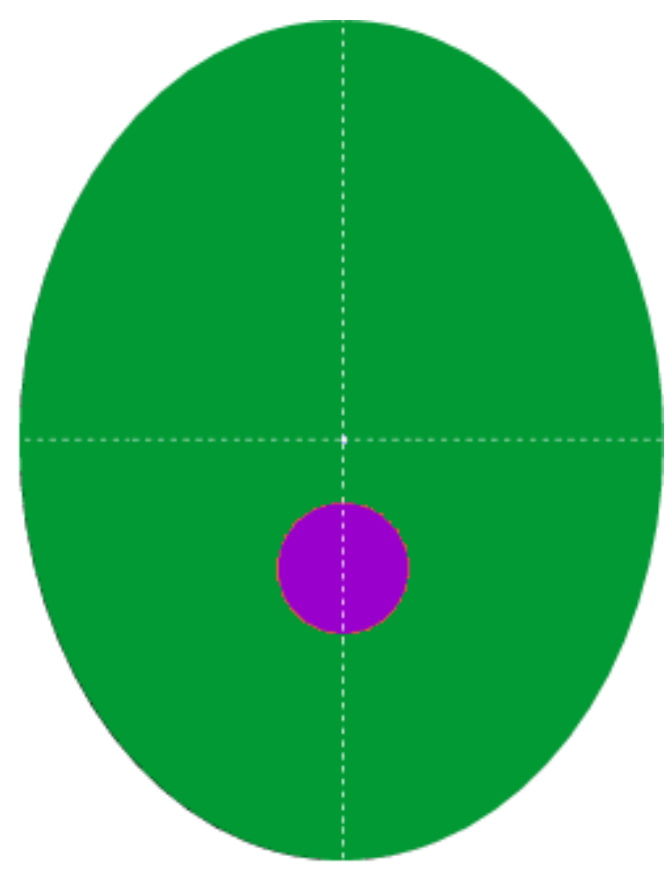

Figura 17: Modelo de célula com incorporação homogênea de ouro no núcleo da célula, para as diferentes concentrações utilizadas na simulação. A cor verde representam a estrutura celular, preenchida com água na simulação, e a região magenta representa o núcleo da célula preenchida com diferentes concentrações de ouro de forma homogênea.

As doses totais no volume do núcleo da célula preenchida com água e água mais ouro foram comparadas em função da concentração de ouro e da energia dos feixes utilizados. Nesta etapa do trabalho foram simulados todos os feixes clínicos estudados neste trabalho, sendo o feixe de fótons de acelerador linear de $6 \mathrm{MV}$, unidades de ortovoltagem de 50, 80, 150 e $250 \mathrm{kVp}$ e uma fonte de braquiterapia com ${ }^{192} \mathrm{Ir}$. A avaliação dos DEFs resultantes foi utilizada para escolha das energias de feixe a serem utilizadas nas simulações com o modelo heterogêneo.

A Tabela 2 sumariza as combinações de feixes e concentrações de AuNPs utlilizadas para este modelo. 
Tabela 2: Energias de feixe e concentrações de AuNPs utilizadas nas simulações do modelo homogêneo.

\begin{tabular}{|c|c|c|}
\hline Equipamentos & Energias & Concentrações (\%) \\
\hline \multirow{3}{*}{ Ortovoltagem } & $50 \mathrm{kVp}$ & 0,$01 ; 0,05 ; 0,1 ; 0,5 ; 1,0$ e 1,1 \\
\cline { 2 - 3 } & $80 \mathrm{kVp}$ & 0,$01 ; 0,05 ; 0,1 ; 0,5 ; 1,0$ e 1,1 \\
\cline { 2 - 3 } & $150 \mathrm{kVp}$ & 0,$01 ; 0,05 ; 0,1 ; 0,5 ; 1,0$ e 1,1 \\
\cline { 2 - 3 } & $250 \mathrm{kVp}$ & 0,$01 ; 0,05 ; 0,1 ; 0,5 ; 1,0$ e 1,1 \\
\hline Braquiterapia & ${ }^{192} \mathrm{Ir}$ & 0,$01 ; 0,05 ; 0,1 ; 0,5 ; 1,0$ e 1,1 \\
\hline Teleterapia & $6 \mathrm{MV}$ & 0,$01 ; 0,05 ; 0,1 ; 0,5 ; 1,0$ e 1,1 \\
\hline
\end{tabular}

Nos estudos realizados com este modelo, as doses totais depositadas no núcleo da célula, preenchido com diferentes concentrações de ouro, foram comparadas em função da concentração de ouro e da energia dos feixes simulados, obtendo-se os DEFs macroscópicos para as condições estudadas.

\subsubsection{Modelo heterogêneo}

Com o intuito de utilizar um modelo mais realístico de incorporação de AuNPs que o modelo homogêneo no estudo dos DEFs, foram realizadas simulações Monte Carlo com nanopartículas individuais e aglomerados de nanopartículas internalizados no núcleo da célula. Desta forma, a implementação deste modelo assume que as nanopartículas estão heterogeneamente incorporadas no núcleo da célula e o aumento de dose considera a fluência de partículas secundárias no entorno de cada nanopartícula ou aglomerado de nanopartículas, bem como as interfaces entre as nanopartículas e o meio biológico.

O pacote PENELOPE foi utilizado para a geração de nanoesferas de 50 a 220 nm incorporadas nos núcleos celulares preenchidos com água. Foram representadas células com uma única nanopartícula (ou aglomerado) internalizada e células com várias nanopartículas (ou aglomerados) internalizadas. 


\subsubsection{Modelo heterogêneo com uma AuNP internalizada}

No modelo heterogêneo, o ouro não é incorporado homogeneamente ao material biológico, de modo que a geometria das nanopartículas de ouro, bem como sua distribuição no meio, é considerada na geometria de simulação.

Nesse modelo, foram simuladas nanopartículas esféricas (ou aglomerados) individuais de ouro, com diâmetro de 50, 100 e 220nm, posicionadas no centro do núcleo da célula, como mostrado na Figura 18. O tamanho e as características geométricas do aglomerado foram obtidos da literatura, a partir de imagens de microscopia eletrônica em experimentos in vitro de incorporação de nanopartículas em células de tumores humanos de próstata (Marques, 2013). Além disso, esses tamanhos de nanopartículas são compatíveis com incorporação de nanopartículas devido ao efeito de permeabilidade e retenção e características de membrana celular para incorporação (Beddoes et al, 2015; Shang, Nienhaus e Nienhaus, 2014).

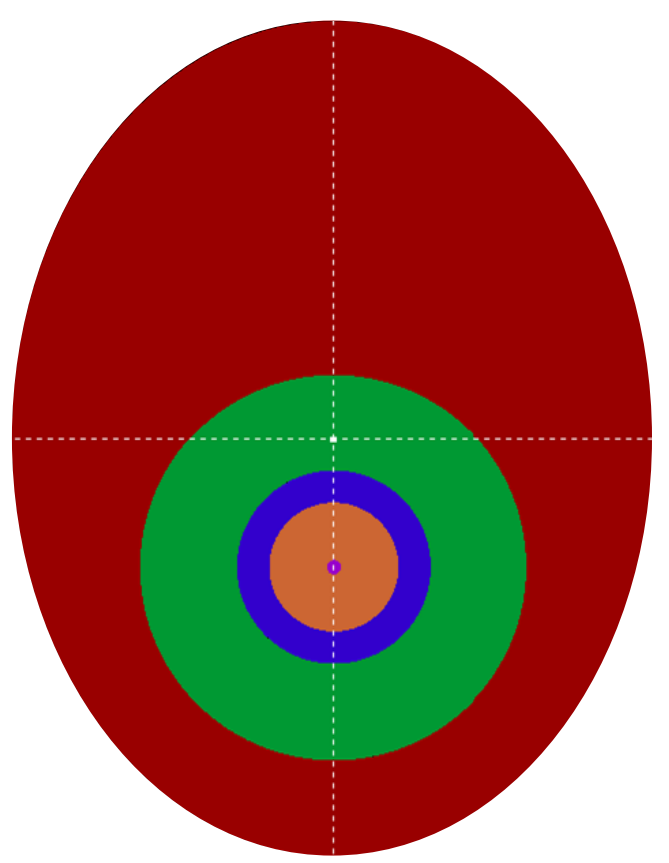

Figura 18: Modelo de célula com nanopartícula de $220 \mathrm{~nm}$ incorporada no núcleo. As diferentes cores representam as estruturas celulares, que foram preenchidas com água na simulação, e a região magenta representa a nanopartícula. 
Nessas simulações, foram selecionados apenas espectros de energia que obtiveram DEFs com maior potencial de utilização clínica a partir dos resultados obtidos nas simulações utilizando o modelo homogêneo. Desta forma, foram utilizados para este modelo somente os feixes de 50 e $150 \mathrm{kVp} \mathrm{e}{ }^{192} \mathrm{Ir}$, representando duas energias de um equipamento de Ortovoltagem, e uma energia de um equipamento de Braquiterapia.

Os mesmos parâmetros de simulação utilizados para o modelo homogêneo foram utilizados nestes estudos, com exceção do número de partículas primárias, que foi de até $10^{12}$ partículas, necessário para obter um máximo de $10 \%$ de incerteza nos DEFs obtidos.

Para cada combinação de tamanho de nanopartícula e espectro foram analisados o DEF, as distribuições de doses, os perfis de dose no entorno das AuNPs e as fluências de fótons e partículas ejetadas pelas nanopartículas.

\subsection{Distribuições de doses e DEF}

O DEF no volume do núcleo celular foi obtido para cada combinação de tamanho de AuNP e espectro de radiação utilizada, sendo dado como a razão da dose no volume com AuNP e a dose no volume do núcleo preenchido somente com água (sem AuNP).

As distribuições de dose foram representadas a partir da matriz de dose disponibilizada pelo PENELOPE no arquivo 3d-dose.dat, utilizando a funcionalidade do pacote para construção de voxels de tamanhos compatíveis com a nanopartícula sendo simulada. Para as AuNPs de $50 \mathrm{~nm}$, os voxels foram construídos com essa mesma dimensão; para os outros tamanhos de AuNP, as dimensões dos voxels foi de um quarto do tamanho da mesma. Para representação das distribuições de doses, toda a matriz de doses foi normalizada pelo ponto de maior dose na borda externa da nanopartícula, posicionado no primeiro voxel externo à nanopartícula. Para leitura e análise dessas matrizes de distribuição de dose foi escrito um programa específico em Matlab®, versão 2011. 


\subsection{Perfis de doses}

Os perfis de dose no entorno das nanopartículas foram traçados a partir das distribuições de doses. Um programa em Matlab®, versão 2011, foi desenvolvido para graficar os valores de dose ao longo de uma linha escolhido dentro da matriz " $3 \mathrm{~d}$ dose.dat".

Para avaliar a influência local das AuNPs foram construídos e analisados os perfis de distribuição dose normalizada passando pelo centro das nanopartículas.Foram determinadas as distâncias das isodoses de 50\%, 20\% e 10\%, a partir da superfície externa da nanopartícula, fornecendo uma medida do alcance do reforço de dose das AuNPs em função dos tamanhos e energias utilizadas ns simulações.

\subsection{Fluência de radiação ejetada pelas AuNPs}

As fluências de fótons e partículas secundárias que emergem das AuNPs foram simuladas para cada tamanho de nanopartícula e espectro de radiação primária utilizadas no modelo heterogêneo com nanopartícula única. A funcionalidade de aquisição de espectros do pacote PENEOPLE foi utilizada, criando-se detectores de fluência na geometria de simulação.

Os detectores de fluência foram representados na geometria como cascas esféricas de $2 \mathrm{~nm}$ de espessura, preenchidos com água e posicionados na superfície externa das nanopartículas. Entretanto, o detector registra não só as partículas que entram no seu interior advindas da AuNP, mas também as que entram em seu interior advindas do volume de água de toda a célula. Desta forma, para a determinação das fluências produzidas apenas pelas AuNPs, cada estudo foi realizado em duas etapas: uma com o volume da nanopartícula preenchida com ouro e outro com o volume da nanopartícula preenchida com água. Assim, a subtração das fluências geradas no detector nessas duas etapas permitiu determinar a fluência de radiação produzida pela presença da nanopartícula de ouro. 


\subsubsection{Modelo heterogêneo com vários aglomerados de AuNPs incorporados}

Neste estudo no modelo heterogêneo foi considerada uma distribuição de seis aglomerados de AuNPs dentro do núcleo. De acordo com o trabalho de Marques (Marques, 2013), consideramos os tamanhos de aglomerados formados dentro do núcleo da célula como sendo de 50,100 e $220 \mathrm{~nm}$ de diâmetro, sendo dois aglomerados de cada tamanho dentro do núcleo. A geometria de simulação da célula com os aglomerados de AuNPs é apresentada na Figura 19.

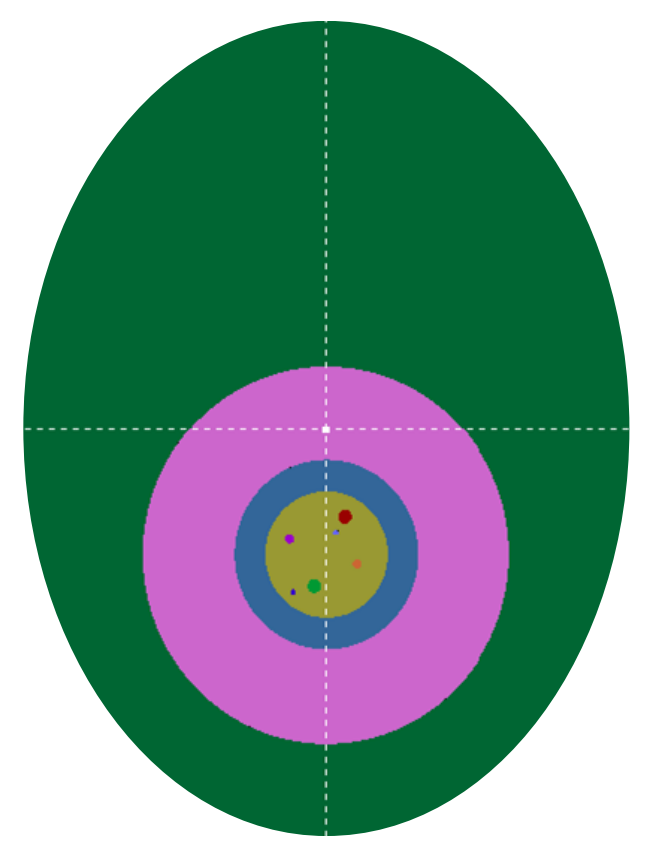

Figura 19: Representação do modelo de incorporação heterogênea de aglomerados de AuNPs na célula. As diferentes cores representam as estruturas celulares, que foram preenchidas com água na simulação, e os pontos coloridos no núcleo representa os diferentes tamanhos de nanopartículas.

Neste estudo foi simulado apenas o feixe de $50 \mathrm{kVp}$, que proporcionou resultados clinicamente significativos de aumento de dose local com a presença das AuNPs. A escolha desse feixe também se baseou no tempo de simulação requerido para a realização de simulações com feixes de energias mais altas, que seria impeditivo para a obtenção de resultados com boa estatística. 
A partir da simulação do modelo de célula com e sem os aglomerados de AuNPs obteve-se o DEF no núcleo da célula, bem como a distribuição de doses resultante da incorporação das AuNPs. As distribuições de dose foram obtidas utilizando o mesmo programa escrito em Matlab® utilizado para o modelo de nanopartícula única internalizada na célula. Para representação das distribuições de doses normalizadas, o voxel externo à nanopartícula, com maior valor de dose, foi utilizado para normalização das doses. 


\section{Resultados e discussões}

Neste capítulo são apresentados os resultados obtidos neste trabalho. Os DEFs e as distribuições de dose obtidas nas simulações dos modelos homogêneo e heterogêneo são apresentadas e discutidas. Os resultados de fluência de fótons e de partículas ejetadas pelas nanopartículas de ouro para o meio biológico são apresentados para o modelo de AuNP única. Finalmente, são apresentadas a distribuição de doses e o DEF obtidos para o modelo heterogêneo em que vários aglomerados de nanopartículas são incorporados no núcleo da célula.

\subsection{Modelo homogêneo}

As simulações de DEF realizadas para o modelo homogêneo de incorporação de ouro nas células foram realizadas para feixes de radiação de uso clínico. A Figura 20 apresenta os DEFs simulados em função da concentração de AuNPs e dos feixes utilizados.

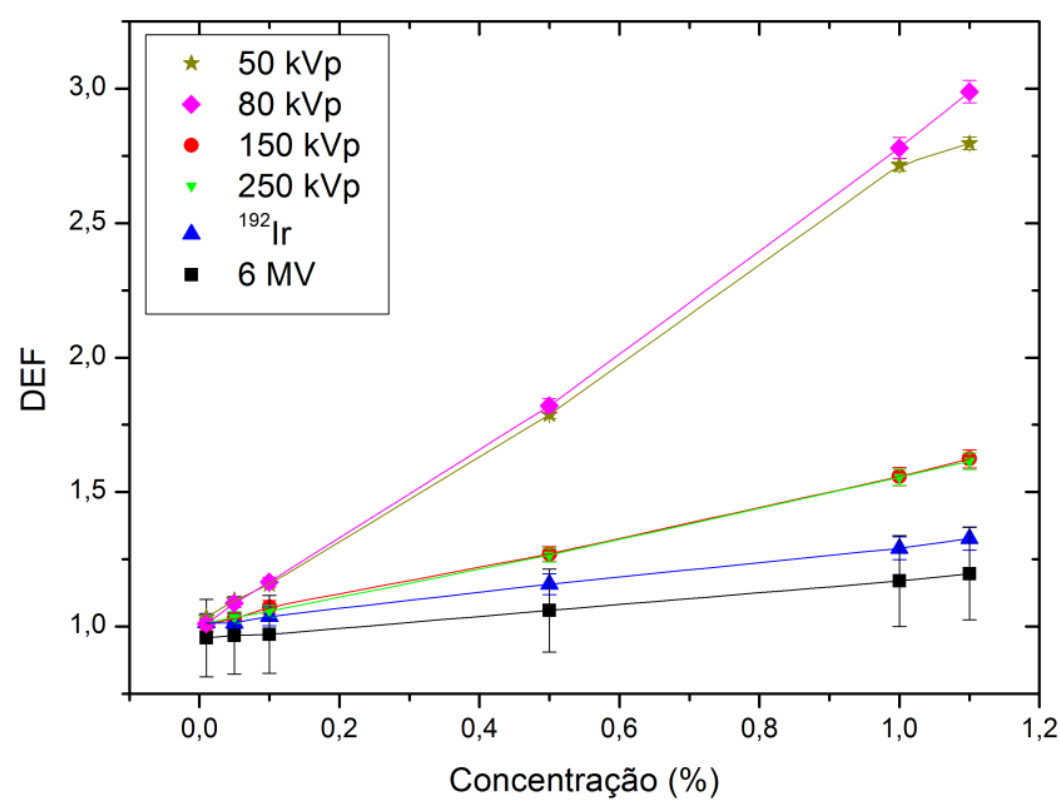

Figura 20: Fatores de aumento de dose em função das concentrações de AuNPs e dos feixes clínicos simulados. 
Através da Figura 20, pode-se notar que há um aumento no DEF em função da concentração de ouro em todo o intervalo de concentrações utilizado e para todos os feixes estudados. Este comportamento era esperado para o modelo homogêneo, já que o DEF nesse modelo é relacionado ao aumento de número atômico efetivo do material onde o ouro está incorporado, de modo que uma maior concentração de ouro resulta em uma maior número atômico efetivo e em um maior DEF. No modelo de incorporação homogênea de ouro na célula, obtivemos resultados que concordam com a literatura, nos mostrando que energias de quilovoltagem e alto $\mathrm{Z}$ contribuem para um alto DEF. Esta combinação tem uma alta probabilidade de produção do efeito fotoelétrico, contribuindo para o aumento do DEF. A utilização de altas concentrações de ouro em sistemas in vivo, entretanto, é limitada pela capacidade de incorporação do material, seja de modo passivo ou ativo, e pela toxicidade resultante. Além disso, em sistema in vivo, a concentração de nanopartículas na solução administrada ao paciente não será totalmente incorporada ao tecido tumoral, de modo que estudos de aumento de dose e de radiossensibilização a baixas concentrações podem proporcionar uma melhor estimativa dos efeitos das nanopartículas em radioterapia.

Pela figura 20 nota-se que aumento no DEF em função da concentração é dependente, ainda, do espectro da radiação primária utilizada. No modelo de incorporação homogênea de ouro na célula, obtivemos resultados que concordam com a literatura, mostrando que energias de quilovoltagem contribuem para um alto DEF e energias mais altas, por sua vez, podem representar um baixo valor de DEF devido à baixa probabilidade de absorção de energia pelo material (Letchman, 2012). Nos resultados obtidos, feixes de 50 e $80 \mathrm{kVp}$ produziram um aumento de dose mais pronunciado (não linear) que feixes de energias mais altas, devido à dependência da probabilidade de atenuação da radiação em função da energia do feixe e do número atômico do material atenuador. Enquanto feixes de baixas energias são atenuados, principalmente, pelo efeito fotoelétrico, em que há absorção total da radiação, as altas energias são atenuadas, principalmente, através do efeito Compton, em que parte da energia do fóton incidente é espalhada, não contribuindo para a dose depositada nas proximidades da nanopartícula.

A Tabela 3 apresenta os DEFs obtidos com as diferentes concentrações de ouro e feixes utilizados. Pode-se notar que para feixes de baixas energias a precisão dos DEFs determinados é melhor, já que há maior absorção de energia, contribuindo para a 
precisão na dose. As incertezas aumentam, ainda, com maiores concentrações, para todos os feixes estudados. Esse resultado está relacionado ao aumento no número de interações, para uma mesma energia, quando se aumenta a concentração de ouro, o que exigiria um tempo maior de simulação para obtenção de uma mesma estatística, para um mesmo feixe, quando se mantém o número de partículas primárias.

Tabela 3: Fatores de aumento de dose para as concentrações de ouro e espectros de energias estudados.

\begin{tabular}{|c|c|c|c|c|c|c|}
\hline \multicolumn{7}{|c|}{ Concentração (\% massa) } \\
\hline Feixes & $\mathbf{0 , 0 1}$ & $\mathbf{0 , 0 5}$ & $\mathbf{0 , 1}$ & 0,5 & 1,0 & 1,1 \\
\hline $50 \mathrm{kVp}$ & $1,03 \pm 0,01$ & $1,10 \pm 0,01$ & $1,16 \pm 0,01$ & $1,79 \pm 0,02$ & $2,72 \pm 0,02$ & $2,80 \pm 0,02$ \\
\hline $80 \mathrm{kVp}$ & $1,01 \pm 0,02$ & $1,09 \pm 0,02$ & $1,17 \pm 0,02$ & $1,82 \pm 0,03$ & $2,78 \pm 0,04$ & $2,99 \pm 0,04$ \\
\hline $150 \mathrm{kVp}$ & $1,01 \pm 0,02$ & $1,03 \pm 0,02$ & $1,07 \pm 0,02$ & $1,27 \pm 0,03$ & $1,56 \pm 0,03$ & $1,62 \pm 0,03$ \\
\hline $250 \mathrm{kVp}$ & $1,01 \pm 0,02$ & $1,03 \pm 0,02$ & $1,06 \pm 0,02$ & $1,27 \pm 0,03$ & $1,55 \pm 0,03$ & $1,61 \pm 0,03$ \\
\hline${ }^{192} \mathbf{I r}$ & $1,01 \pm 0,03$ & $1,01 \pm 0,03$ & $1,04 \pm 0,04$ & $1,16 \pm 0,04$ & $1,29 \pm 0,04$ & $1,33 \pm 0,04$ \\
\hline $6 \mathrm{MV}$ & $0,96 \pm 0,14$ & $0,97 \pm 0,14$ & $0,97 \pm 0,14$ & $1,06 \pm 0,15$ & $1,17 \pm 0,17$ & $1,20 \pm 0,17$ \\
\hline
\end{tabular}

Pode-se concluir, através destes resultados, que as energias que proporcionam um maior DEF são os feixes de espectros em algumas dezenas de quilovoltagem, como os feixes de 50 e $80 \mathrm{kVp}$, para todas as concentrações de ouro. Um segundo grupo de feixes, que produzem DEFs intermediários, são aqueles de até algumas centenas de quiloeletronvolts, produzindo DEFs significativos quando combinados com altas concentrações de ouro. O feixe de teleterapia de megavoltagem estudado, de $6 \mathrm{MV}$ típico de acelerador linear, proporcionou os menores DEFs em todas as concentrações estudadas. Esses resultados sugerem que o uso de AuNPs em radioterapia com feixes de megavoltagem exigiriam altíssimas concentrações de nanopartículas ou o uso de materiais de maior número atômico para proporcionar um aumento de dose que justificasse o uso clínico dessa técnica de tratamento. Sendo assim, para as simulações do modelo heterogêneo, as energias escolhidas para estudo foram de $50 \mathrm{kVp}$ e $150 \mathrm{kVp}$, bem como a fonte de Irídio-192, por serem energias de fácil acesso e ampla utilização clínica. 
No modelo homogêneo, o aumento da concentração de ouro sempre proporcionará aumento de dose, dado que todo o volume do núcleo é utilizado para o cálculo do DEF e não há a possibilidade de que uma nanopartícula vizinha atenue a fluência emitida pela outra nanopartícula. Desta forma, as concentrações de ouro nominais não correspondem à concentração de AuNPs efetivamente incorporadas ao tecido. Assim, os resultados obtidos nesse modelo não são realísticos e foram utilizados apenas como uma primeira aproximação do aumento de dose que pode ser obtido com a incorporação de AuNPs em radioterapia, auxiliando na escolha dos feixes de maior potencialidade para implementação do modelo heterogêneo.

\subsection{Modelo Heterogêneo}

Nesta seção são apresentados os resultados obtidos nas simulações do modelo heterogêneo de incorporação de uma AuNP ou de um aglomerado de AuNPs nas células.

\subsubsection{Modelo heterogêneo com uma AuNP incorporada}

Com as simulações do modelo heterogêneo com somente uma AuNP na célula foi possível avaliar a fluência de partículas que entram e saem da AuNP e a distribuição de dose e o perfil de dose no entorno de cada nanopartícula.

\subsubsection{Fluência de radiação ejetada pelas AuNPs}

Para as energias e tamanhos de AuNPs selecionados foi realizado um levantamento da fluência de radiação que entra e que é ejetada do volume da nanopartícula. As Figuras 21 e 22 apresentam as fluências de fótons e elétrons, respectivamente, entrando e saindo do volume das nanopartículas para o feixe de 50 $\mathrm{kVp}$. As Figuras 23 e 24 apresentam os mesmos resultados para o feixe de $150 \mathrm{kVp}$ e as Figuras 25 e 26 para o feixe de ${ }^{192}$ Ir. 
Em todos os resultados obtidos, as fluências relativas de fótons entrando e saindo do volume das AuNPs são condizentes com as energias dos feixes primários utilizados. Nota-se, ainda, para todas as energias estudadas, que as fluências de fótons que entram nas AuNPs são significativamente maiores que as fluências dos elétrons ejetados, indicando que a maioria dos elétrons produzidos nas nanopartículas é auto atenuada antes de ser ejetada para o meio biológico.

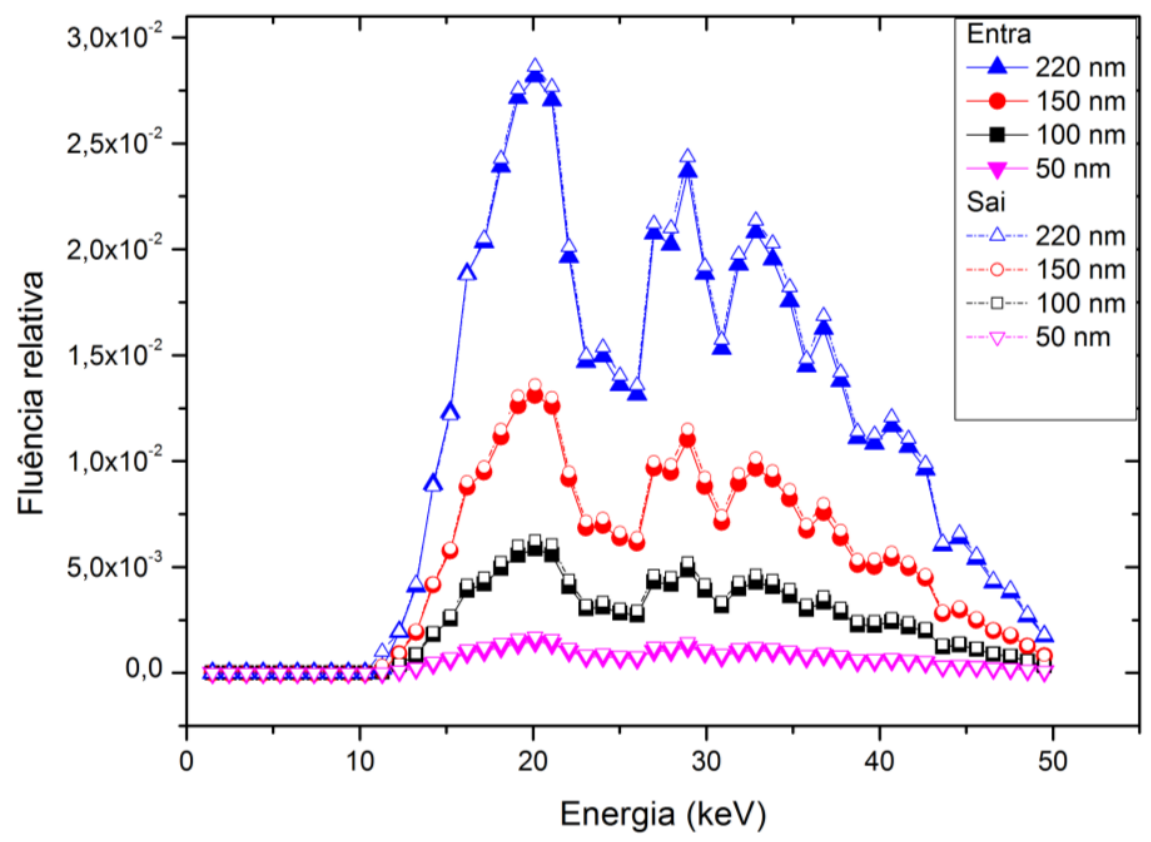

Figura 21: Fótons que entram e saem das AuNPs para o feixe de $50 \mathrm{kVp}$. 


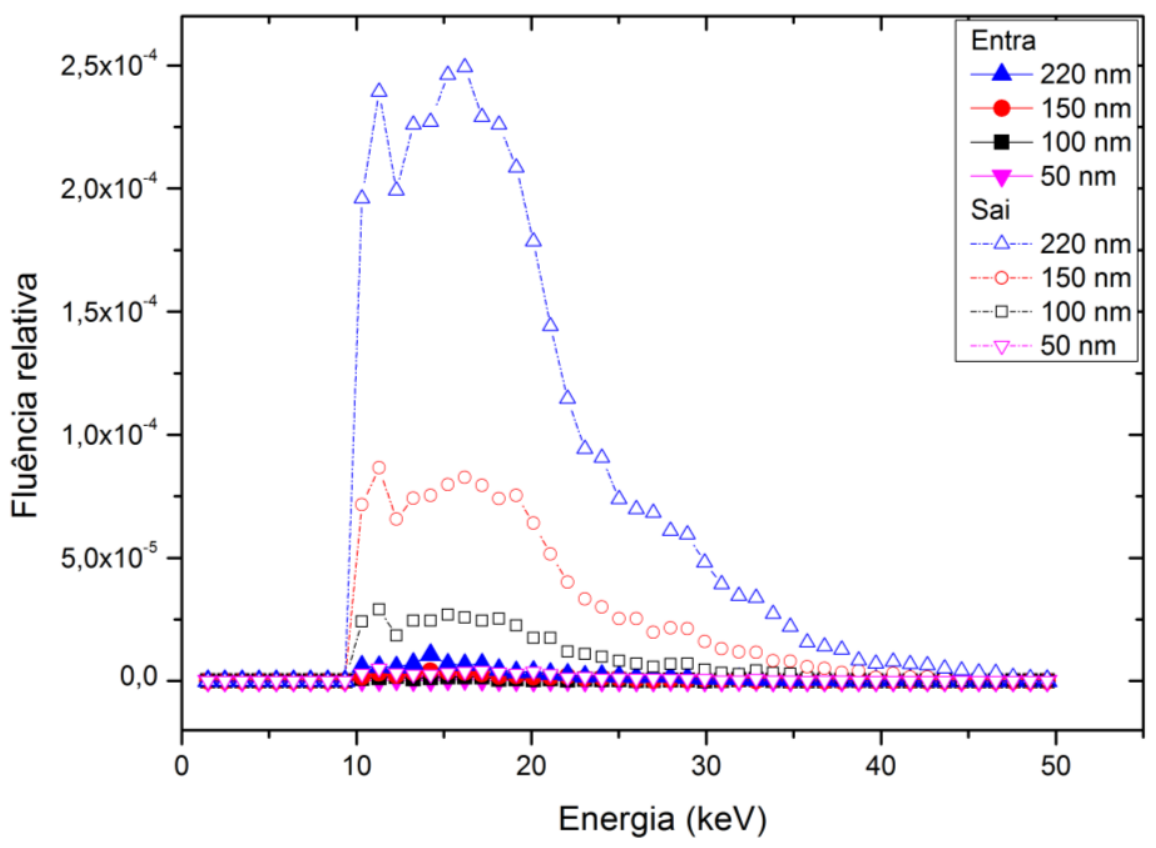

Figura 22: Elétrons que entram e saem das AuNPs para o feixe de $50 \mathrm{kVp}$.

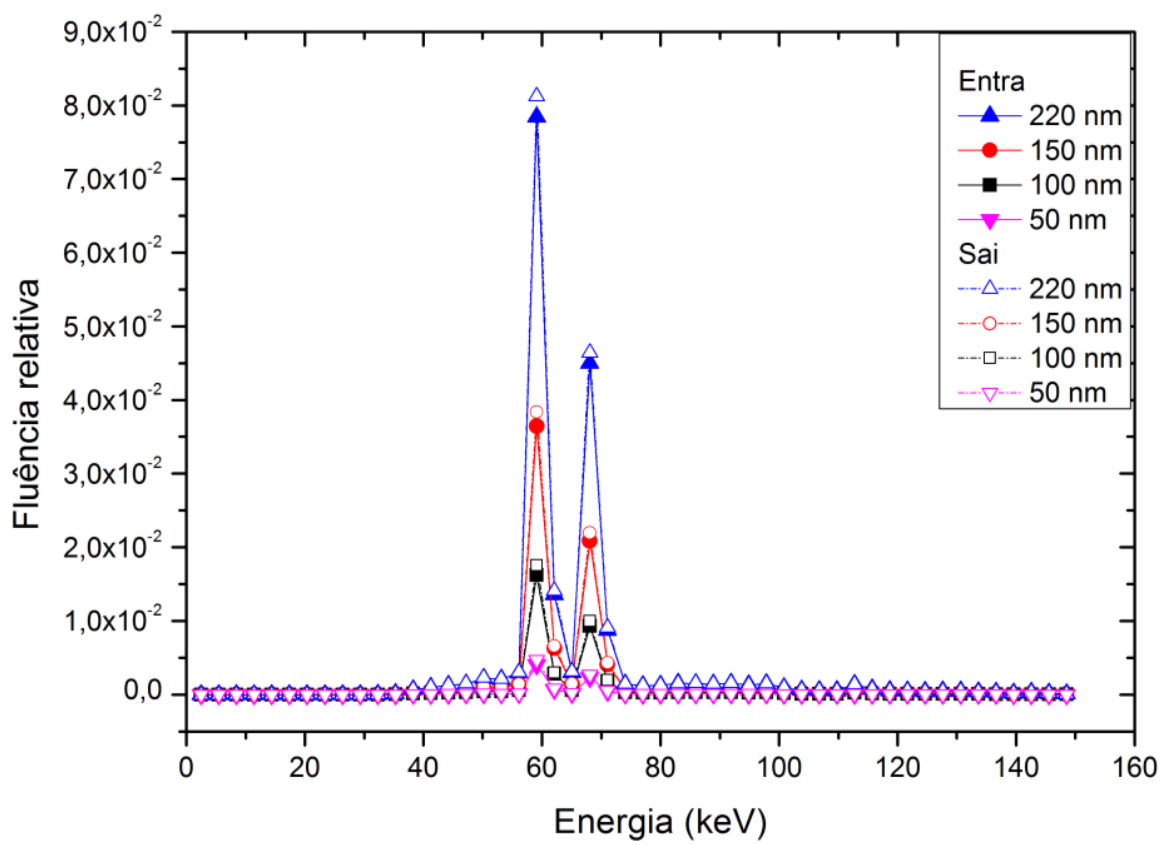

Figura 23: Fótons que entram e saem das AuNPs para o feixe de $150 \mathrm{kVp}$. 


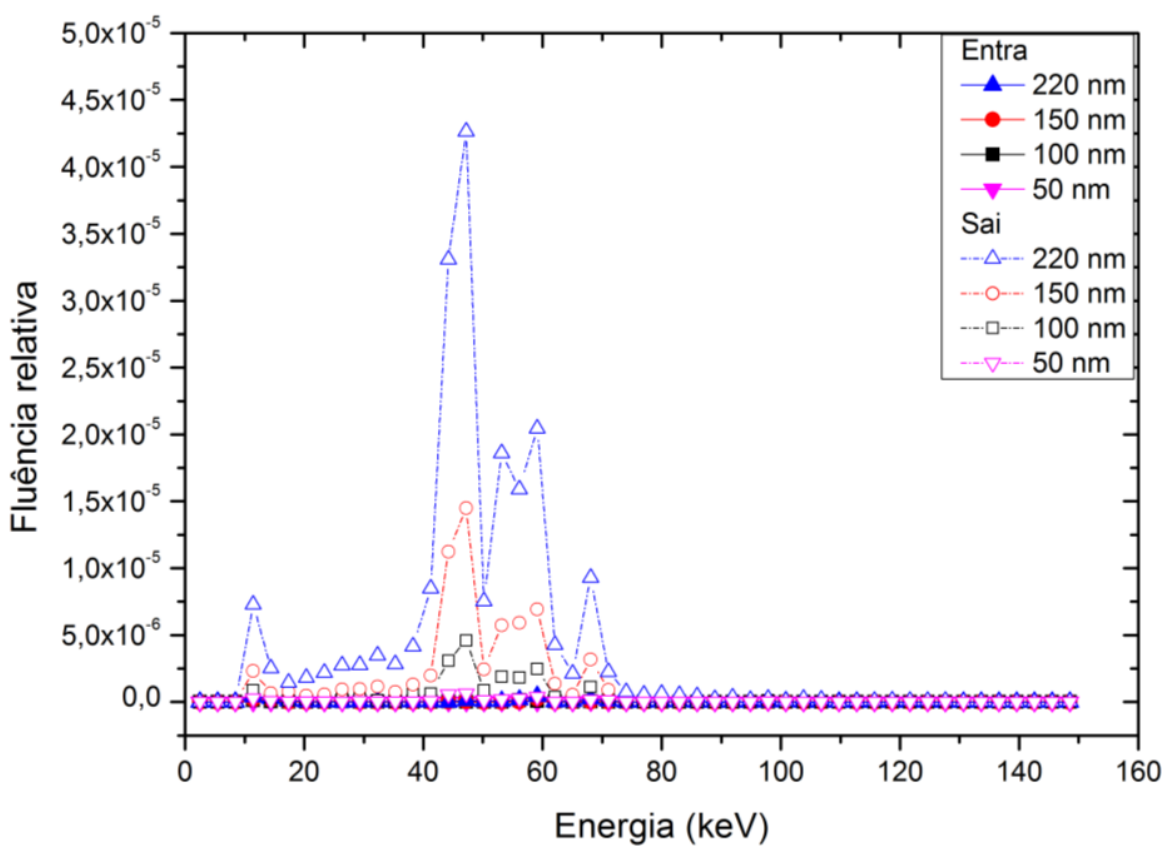

Figura 24: Elétrons que entram e saem da AuNP para o feixe de $150 \mathrm{kVp}$.

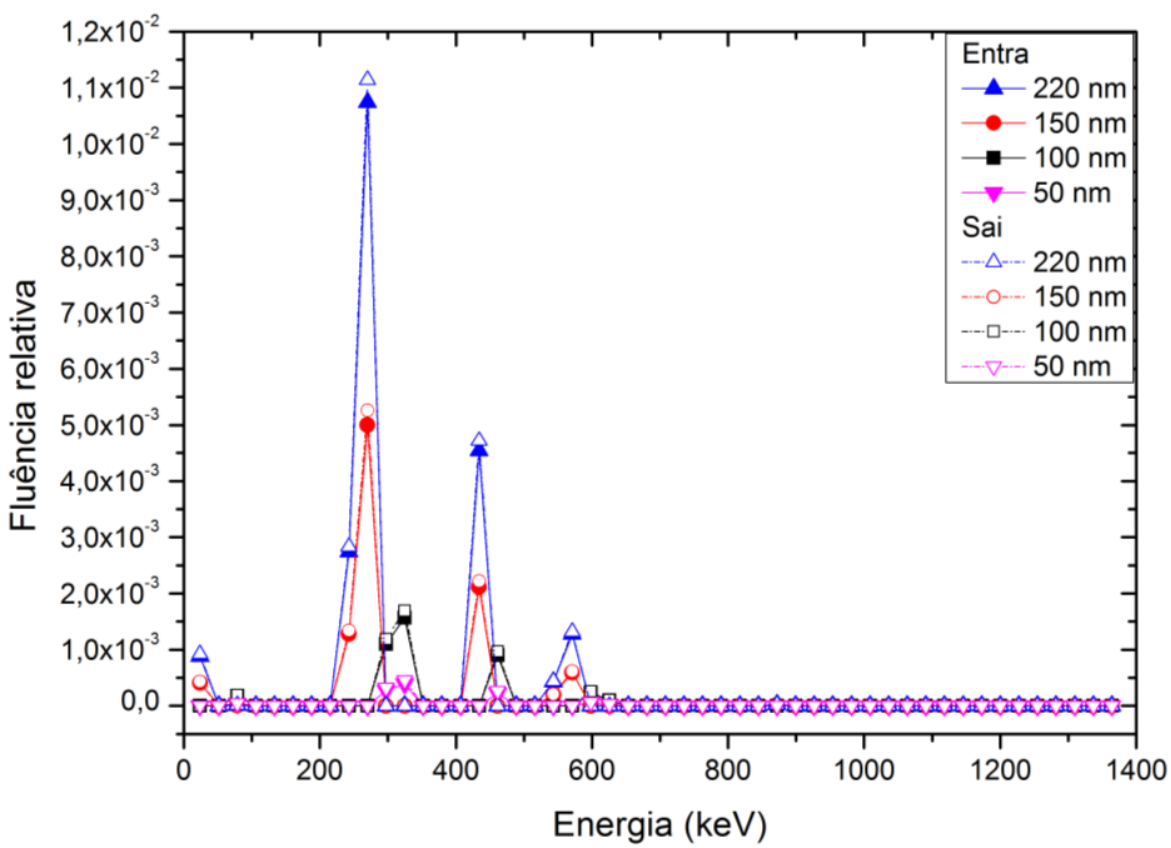

Figura 25: Fótons que entram e saem das AuNPs para o feixe de ${ }^{192}$ Ir. 


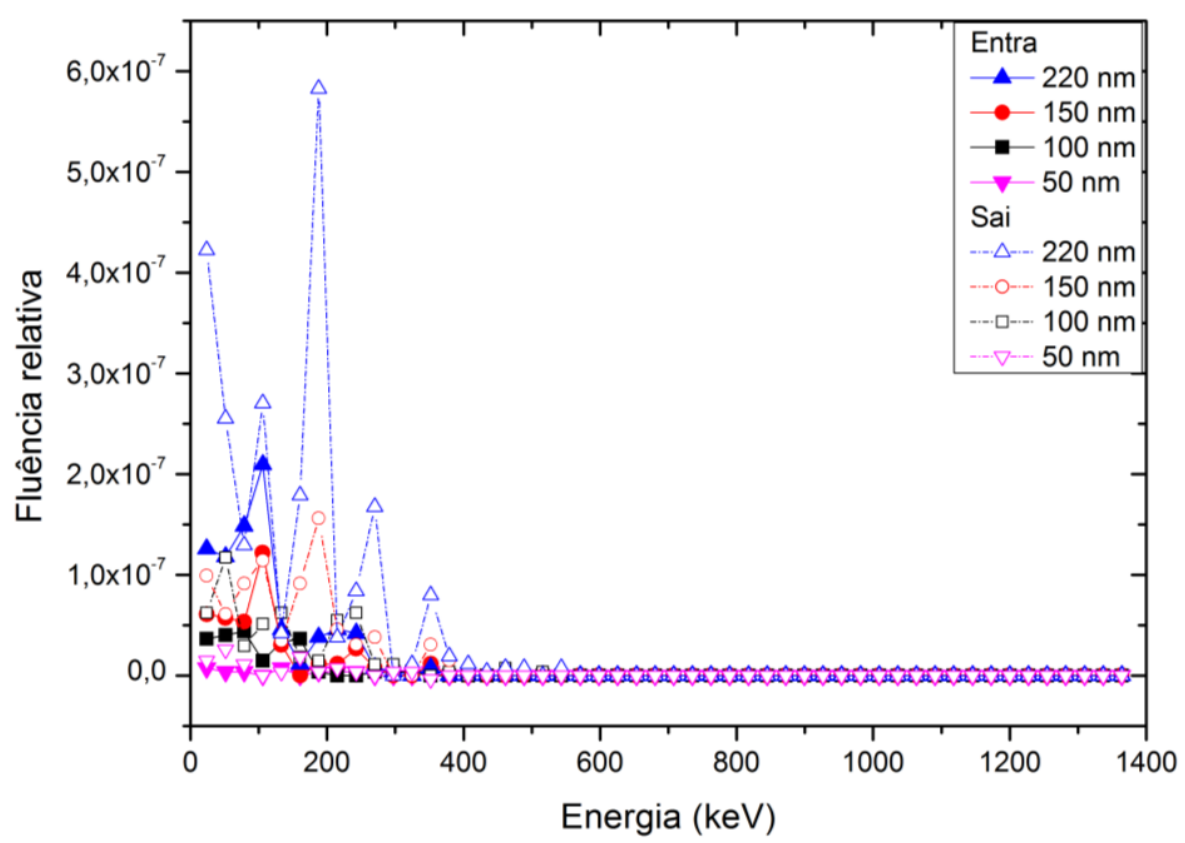

Figura 26: Elétrons que entram e saem da AuNP para o feixe de ${ }^{192} \mathrm{Ir}$.

De modo geral, as fluências de elétrons sendo ejetados pelas AuNPs são significativamente maiores que as de elétrons entrando nas mesmas, sugerindo que a nanopartícula realmente reforça a fluência das partículas carregadas no meio em que estão internalizadas, proporcionando aumento de dose. Além disso, as nanopartículas de maior diâmetro ejetam mais elétrons para o meio biológico que as menores, devido ao maior volume e área superficial destas, aumentando sua atenuação e a formação de radiação secundária. O aumento do tamanho das AuNPs, entretanto, pode aumentar a auto atenuação nas mesmas, podendo causar diminuição de dose no meio biológico, efeito semelhante ao do aumento de concentração de AuNPs internalizadas.

Fotoelétrons produzidos nas linhas $\mathrm{K}$ e L do ouro têm, respectivamente, energias de, aproximadamente, 80 e 11 à $14 \mathrm{keV}$. Já os elétrons Compton produzidos no ouro têm energias variadas. Os elétrons Compton produzidos no ouro pela energia mais provável no espectro do ${ }^{192} \mathrm{Ir}$, por exemplo, terá energia de, aproximadamente, $200 \mathrm{keV}$ (NIST, 2017a, NIST, 2017 b).

Para o feixe primário de $50 \mathrm{kVp}$, enquanto que a Figura 21 mostra que o espectro de fótons entrando nas AuNPs possui alta fluência relativa em energias próximas de $20 \mathrm{keV}$, a Figura 22 mostra que as fluências relativas mais prováveis de partículas carregadas produzidas dentro das AuNPs aparecem em energias entre 10 e 20 
$\mathrm{keV}$, indicando a fluência de entrada deve estar sendo atenuada através do efeito fotoelétrico em energias próximas às linhas L de emissão do ouro.

Para o feixe de 150 kVp, a Figura 23 mostra que os fótons que entram na AuNP têm, principalmente, energias entre 60 e $65 \mathrm{keV}$, enquanto que a Figura 24 mostra que os elétrons produzidos por esses fótons têm energias mais variadas, com picos próximos de $10 \mathrm{keV}$ e entre 40 e $70 \mathrm{keV}$. Essa maior dispersão da fluência energética das partículas carregadas formadas na AuNP indica uma maior proporção de ocorrência do efeito Compton em relação ao feixe de $50 \mathrm{kVp}$. Além disso, para o feixe primário de $150 \mathrm{kVp}$, a fluência de elétrons ejetada é menor que para o feixe de $50 \mathrm{kVp}$, contribuindo relativamente menos com o aumento de dose local. Isto se deve, por um lado, à menor probabilidade de interação com o aumento da energia do feixe, e por outro lado, a uma maior parcela de auto atenuação, causada dentro da AuNP. Com aumento da energia do fóton incidente, o processo de atenuação ocorrerá em camadas mais internas da AuNP, de modo que o elétron produzido terá que percorrer um caminho maior dentro do ouro antes de ser ejetado. Desta forma, os elétrons produzidos serão mais atenuados pela própria nanopartícula, diminuindo a fluência ejetada.

Para o feixe de ${ }^{192}$ Ir nota-se, nas Figuras 25 e 26, uma dispersão da energia das partículas carregadas ejetadas pela AuNP em relação à energia dos fótons incidentes, do mesmo modo que o observado para o feixe de $150 \mathrm{kVp}$. Partículas carregadas de até, aproximadamente, $400 \mathrm{keV}$ são produzidas dentro da nanopartícula pela atenuação da radiação primária de mais alta energia através da atenuação pelo efeito Compton, com contribuições importantes em regiões de energias de até $200 \mathrm{keV}$. Para o feixe de ${ }^{192} \mathrm{Ir}$ nota-se, ainda, uma queda ainda mais acentuada na fluência relativa de partículas carregadas em relação à produzida pelos feixes de $50 \mathrm{kVp}$, assim como observado para o feixe de $150 \mathrm{kVp}$. Entretanto, para essa energia, a baixa fluência de elétrons pode ser compensada por sua baixa energia, aumentando a contribuição para a dose local.

Uma vez que, em nossas análises as principais partículas criadas são fótons e elétrons, devido a interação do feixe de fótons de baixa energia com um material de alto número atômico ter uma maior probabilidade de efeito fotoelétrico, como já citado neste trabalho. Com base nesta teoria podemos dizer que é possível uma alta contribuição de elétrons para o DEF fora da nanopartícula quando se tem baixa energia. 


\subsubsection{Distribuição de doses e DEF}

As Figuras 27 a 29 apresentam as distribuições de doses para as energias de 50 kVp, 150 kVp e ${ }^{192} \mathrm{Ir}$, respectivamente, para AuNPs de (a) 50, (b) 100 e (c) $220 \mathrm{~nm}$. Em todas as distribuições de doses apresentadas, as doses foram normalizadas para a dose do voxel de maior dose na borda externa da nanopartícula. Desta forma, as escalas de doses normalizadas excedem a dose de $100 \%$ devido às doses na entrada do feixe serem maiores que as doses na profundidade das AuNPs.

Para os feixes e os três tamanhos de AuNPs utilizados é possível visualizar que tamanhos maiores de nanopartículas influenciam mais a dose local, conforme esperado a partir da maior fluência de partículas ejetadas obtida para essas nanopartículas. Esse aumento de dose local ocorre, ainda, predominantemente em baixas energias. Para a energia de ${ }^{192}$ Ir no tamanho de $50 \mathrm{~nm}$, não é possível visualizar a presença da AuNP, devido à baixa contribuição de elétrons espalhados para o meio biológico com um baixo aumento local de dose, como já era esperado pelos resultados obtidos com o modelo homogêneo. 


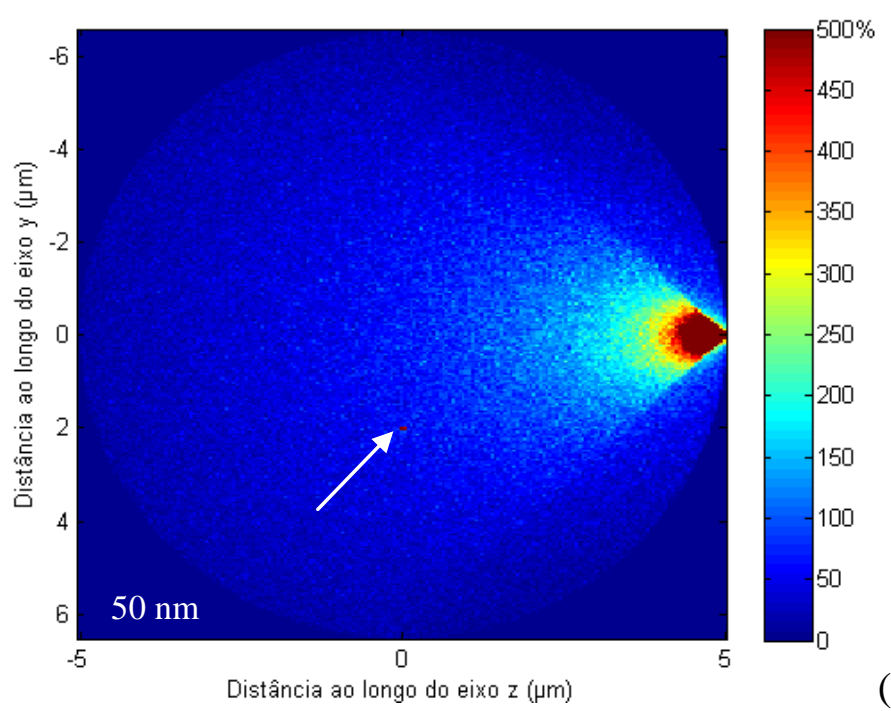

(a)

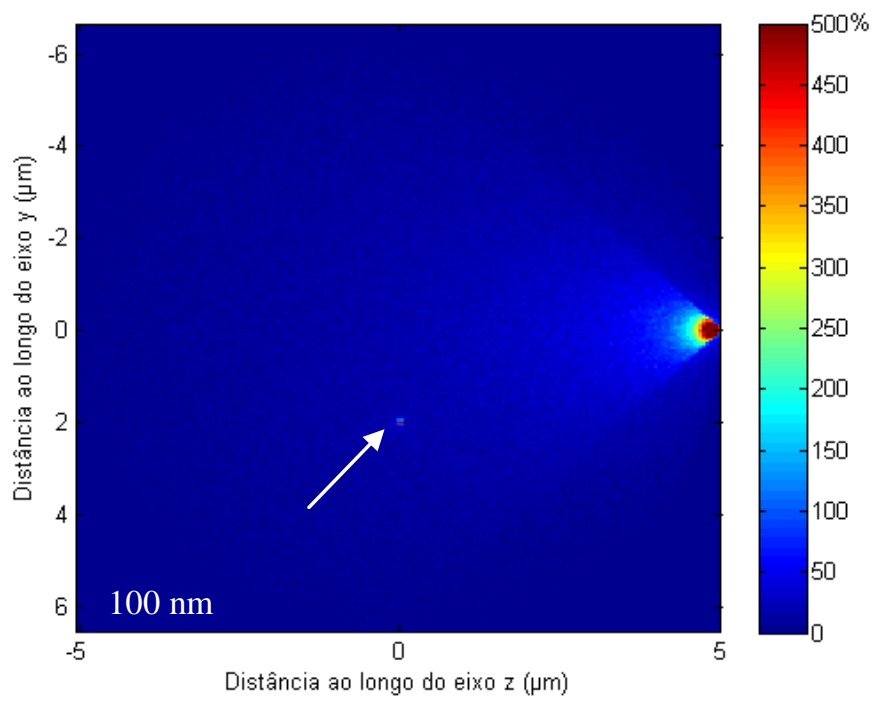

(b)

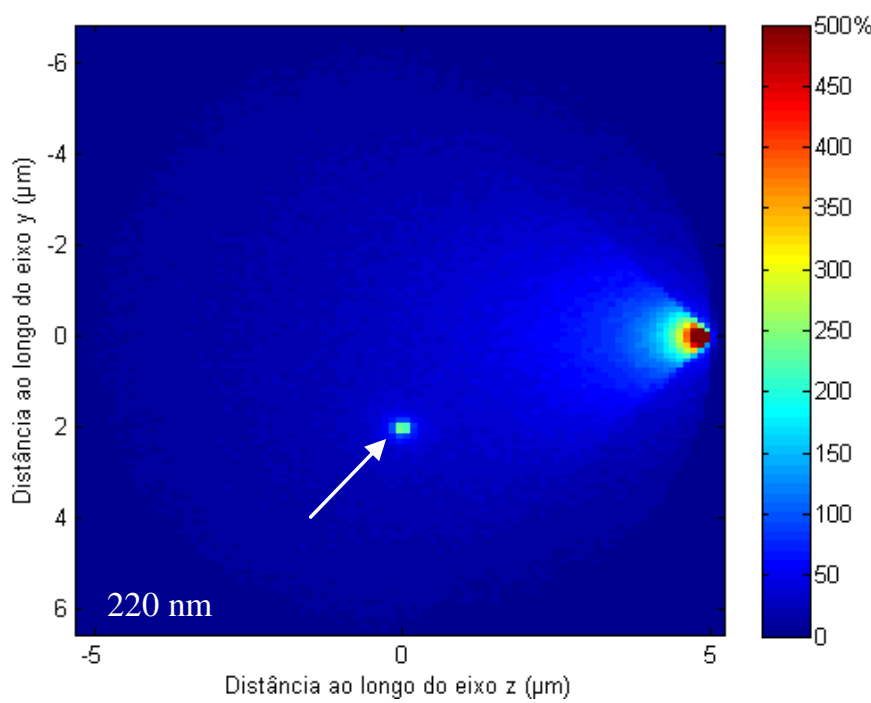

(c)

Figura 27: Distribuição de doses para uma única AuNP incorporada e feixe de $50 \mathrm{kVp}$ : (a) $50 \mathrm{~nm}$, (b) $100 \mathrm{~nm}$ e (c) $220 \mathrm{~nm}$. 


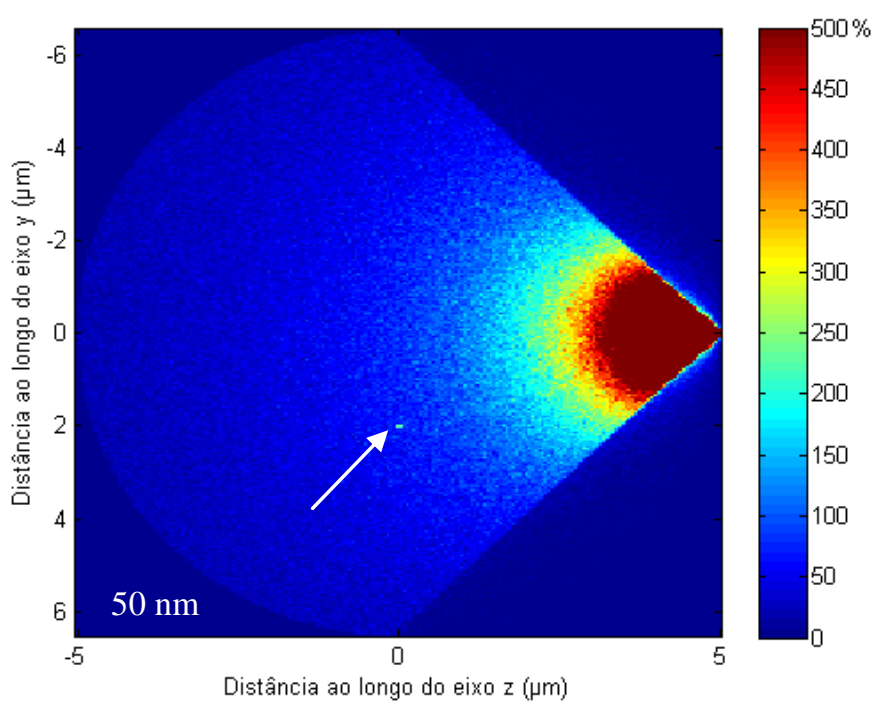

(a)

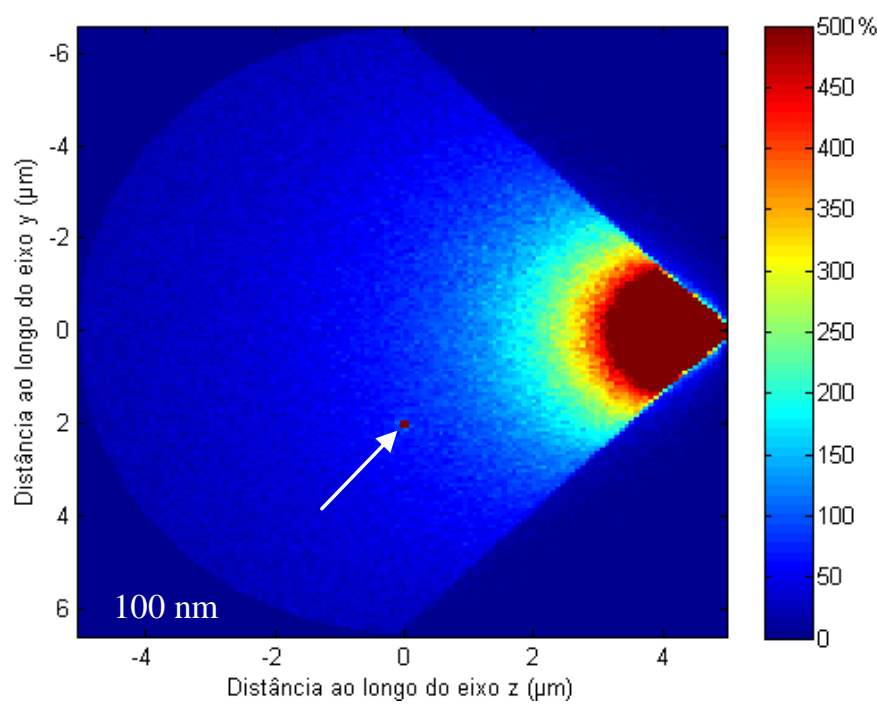

(b)

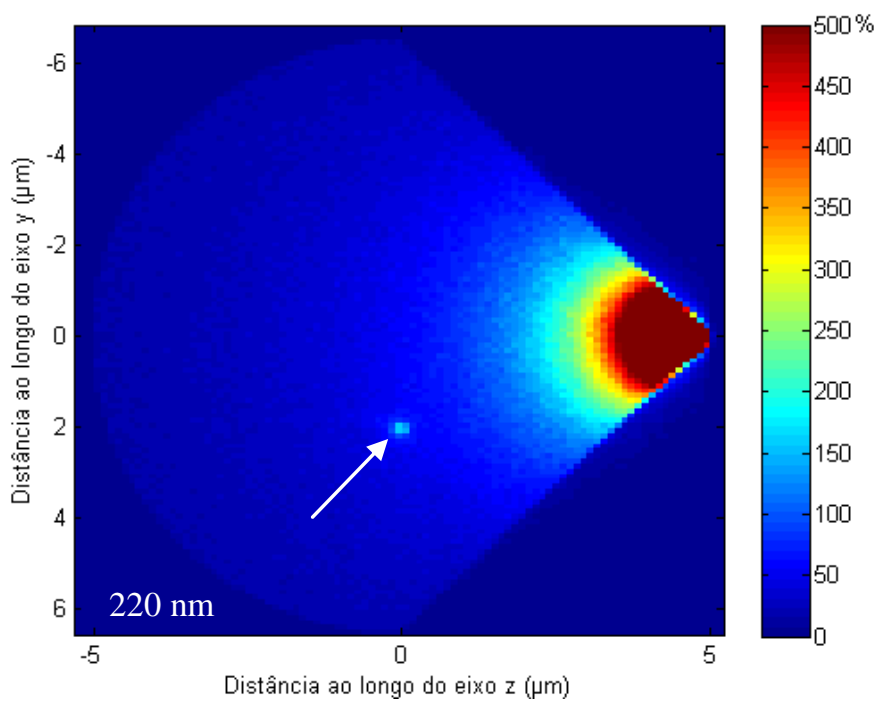

(c)

Figura 28: Distribuição de doses para uma única AuNP incorporada e feixe de $150 \mathrm{kVp}$ : (a) $50 \mathrm{~nm}$, (b) $100 \mathrm{~nm}$ e (c) $220 \mathrm{~nm}$. 


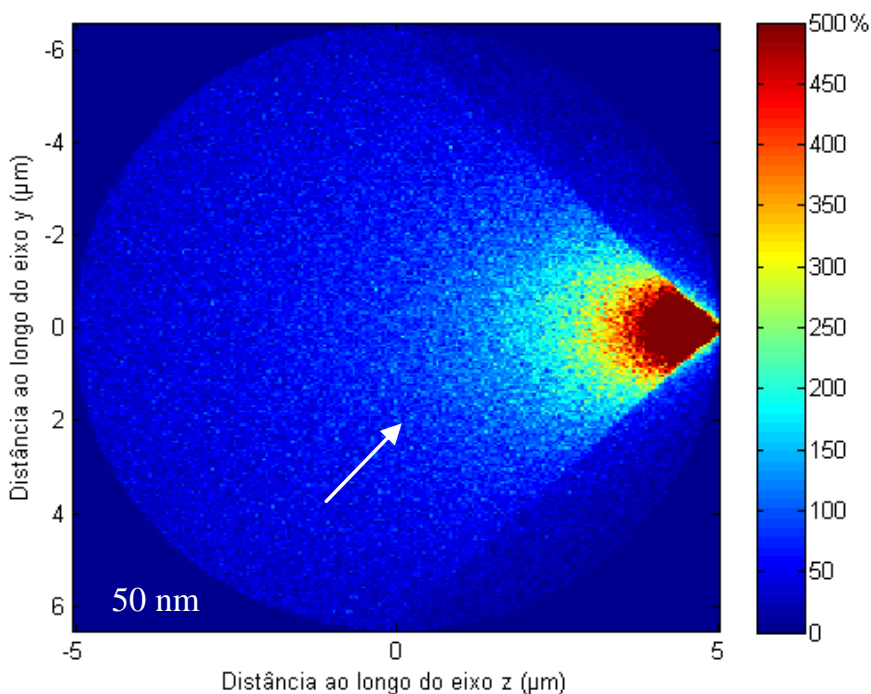

(a)

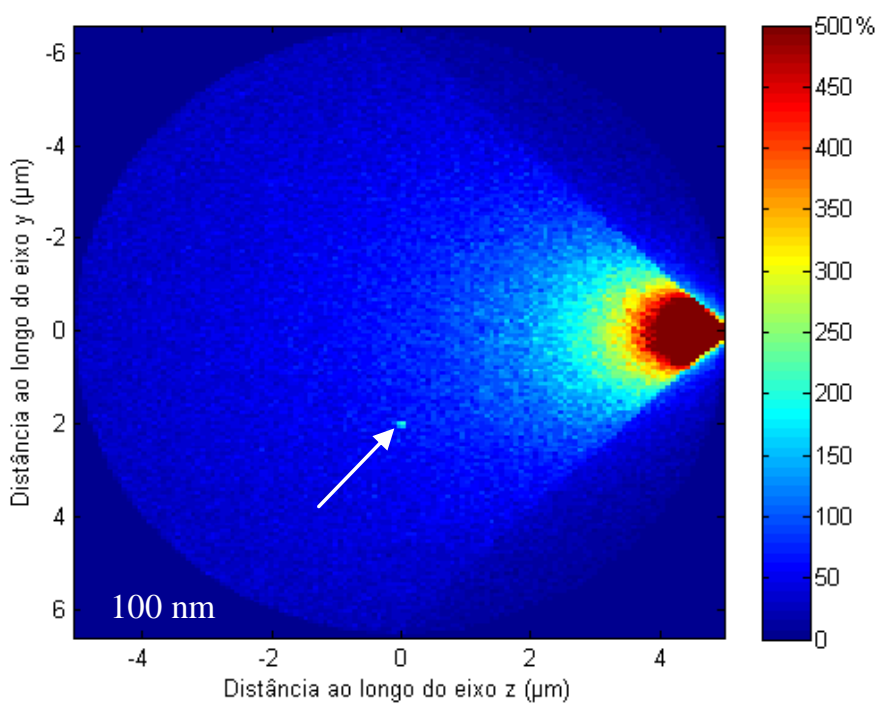

(b)

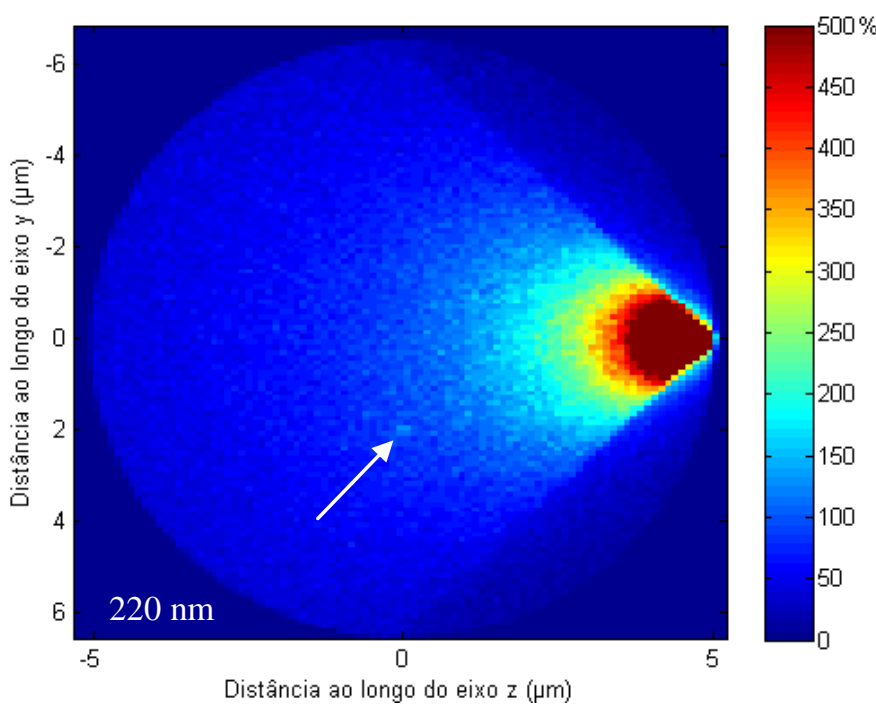

(c)

Figura 29: Distribuição de doses para uma única AuNP incorporada e feixe de ${ }^{192}$ Ir: (a) $50 \mathrm{~nm}$, (b) $100 \mathrm{~nm}$ e (c) $220 \mathrm{~nm}$. 
As simulações realizadas com os diferentes feixes e com as nanopartículas de diferentes tamanhos permitiram avaliar os DEFs obtidos no modelo heterogêneo com AuNP única, apresentados na Figura 30. Nessa análise foram, ainda, incorporados resultados obtidos para AuNPs de $150 \mathrm{~nm}$.

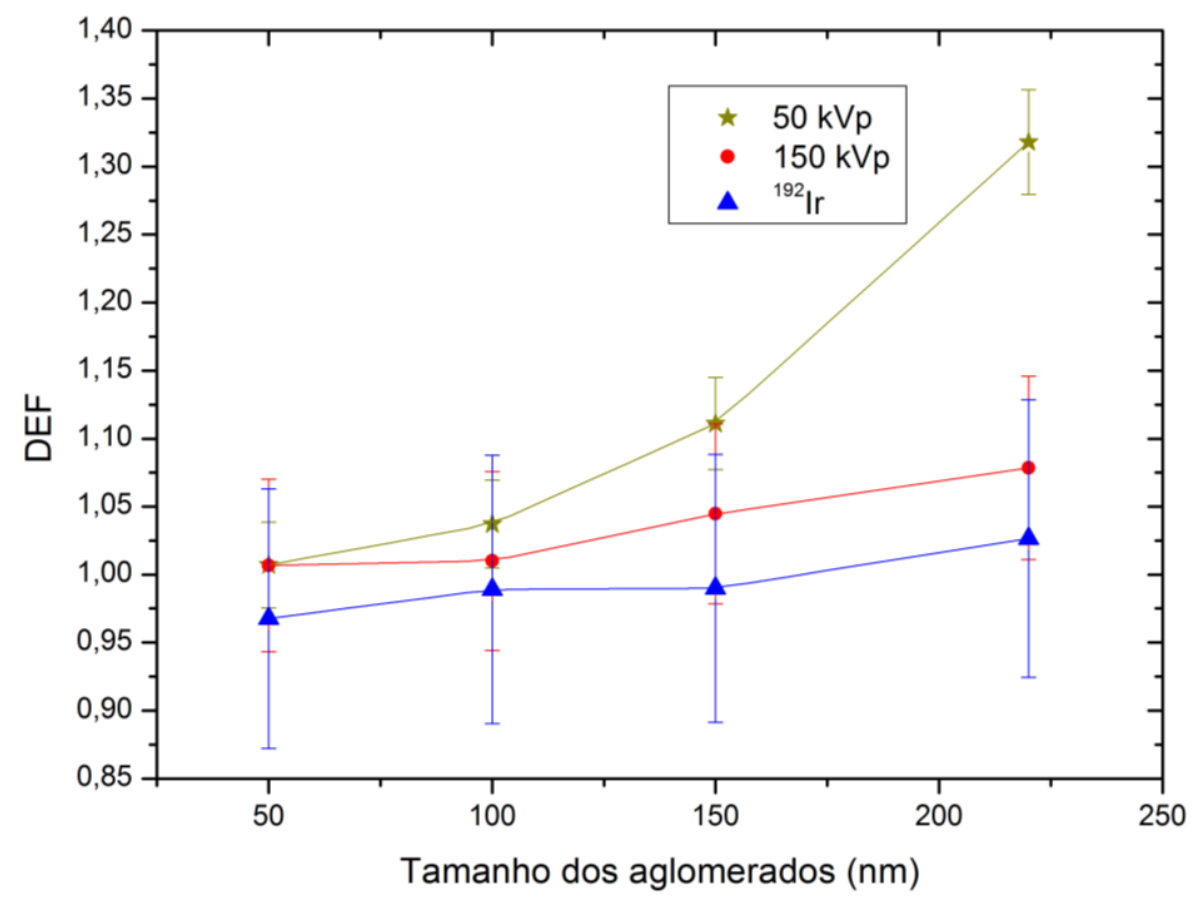

Figura 30: Fatores de aumento de dose em função dos tamanhos dos aglomerados de AuNPs e dos feixes clínicos simulados.

De modo geral, os DEFs aumentam com o aumento do tamanho das AuNPs (ou aglomerados de AuNPs). Observa-se que a energia de $50 \mathrm{kVp}$ é a que apresenta os maiores DEFs, principalmente em tamanhos de AuNP maiores, com comportamento não linear em função do tamanho da AuNP. As incertezas obtidas para as demais energias são maiores que para o feixe de $50 \mathrm{kVp}$ e os DEFs menos significativos, como esperado a partir dos resultados obtidos com o modelo homogêneo e das fluências de partículas carregadas produzidas nessas energias.

Os valores de DEF para os feixes e tamanhos de AuNP avaliados são apresentados na Tabela 4 . 
Tabela 4: Fator de aumento de dose para os feixes e diferentes tamanhos de AuNP estudados no modelo heterogêneo.

\begin{tabular}{|c|c|c|c|c|}
\hline & \multicolumn{4}{|c|}{ Diâmetro das AuNPs (nm) } \\
\hline Feixes & $\mathbf{5 0}$ & $\mathbf{1 0 0}$ & $\mathbf{1 5 0}$ & $\mathbf{2 2 0}$ \\
\hline $\mathbf{5 0} \mathbf{~ k V p}$ & $1,01 \pm 0,03$ & $1,04 \pm 0,03$ & $1,11 \pm 0,03$ & $1,32 \pm 0,04$ \\
\hline $\mathbf{1 5 0} \mathbf{~ k V p}$ & $1,01 \pm 0,06$ & $1,01 \pm 0,07$ & $1,04 \pm 0,07$ & $1,08 \pm 0,07$ \\
\hline${ }^{192} \mathbf{I r}$ & $0,97 \pm 0,09$ & $0,99 \pm 0,09$ & $0,99 \pm 0,09$ & $1,03 \pm 0,10$ \\
\hline
\end{tabular}

Pode-se notar que, mesmo para combinações de baixas energias e grandes tamanhos de AuNPs, os DEFs encontrados para o modelo heterogêneo são menores que aqueles encontrados no modelo homogêneo. Deve-se levar em consideração, entretanto, que as concentrações de ouro nos estudos dos dois modelos é diferente. Para a energia de $50 \mathrm{kVp}$ e nanopartícula de $220 \mathrm{~nm}$ o DEF encontrado foi de 1,32 $\pm 0,04$. Para efeito de comparação, esse DEF, para a mesma energia, no modelo homogêneo corresponderia a uma concentração de $0,2 \%$ de ouro internalizado no núcleo. Entretanto, a concentração real associada a essa AuNP é de 0,3\%, quando considerado apenas o volume do núcleo. Essa discrepância mostra, mais uma vez, a inexatidão do modelo homogêneo de incorporação de AuNPs em radioterapia. Além disso, a avaliação de radioterapia com AuNPs baseada somente no DEF (macroscópico) é inadequada pois não leva em consideração aspectos locais de interações no entorno das nanopartículas, que podem ser fundamentais na avaliação da radiossensibilização celular.

\subsubsection{Perfis de doses}

Através das distribuições de doses obtidas com uma única nanopartícula no núcleo foi possível determinar o alcance da influência das AuNPs nas doses em seu entorno. Foi realizada uma avaliação das regiões das isodoses de 50, 20 e 10\% para os diferentes tamanhos de AuNP, como demonstrado nas Figuras 31 a 33 para os feixes de 50 e $150 \mathrm{kVp}$ e ${ }^{192} \mathrm{Ir}$, respectivamente. As linhas tracejadas nas figuras representam as posições das AuNPs e as setas representam as posições das isodoses de interesse. O perfil para o tamanho de $50 \mathrm{~nm}$ e energia de ${ }^{192}$ Ir não foi apresentado por não apresentar aumento de dose estatisticamente significativo. 

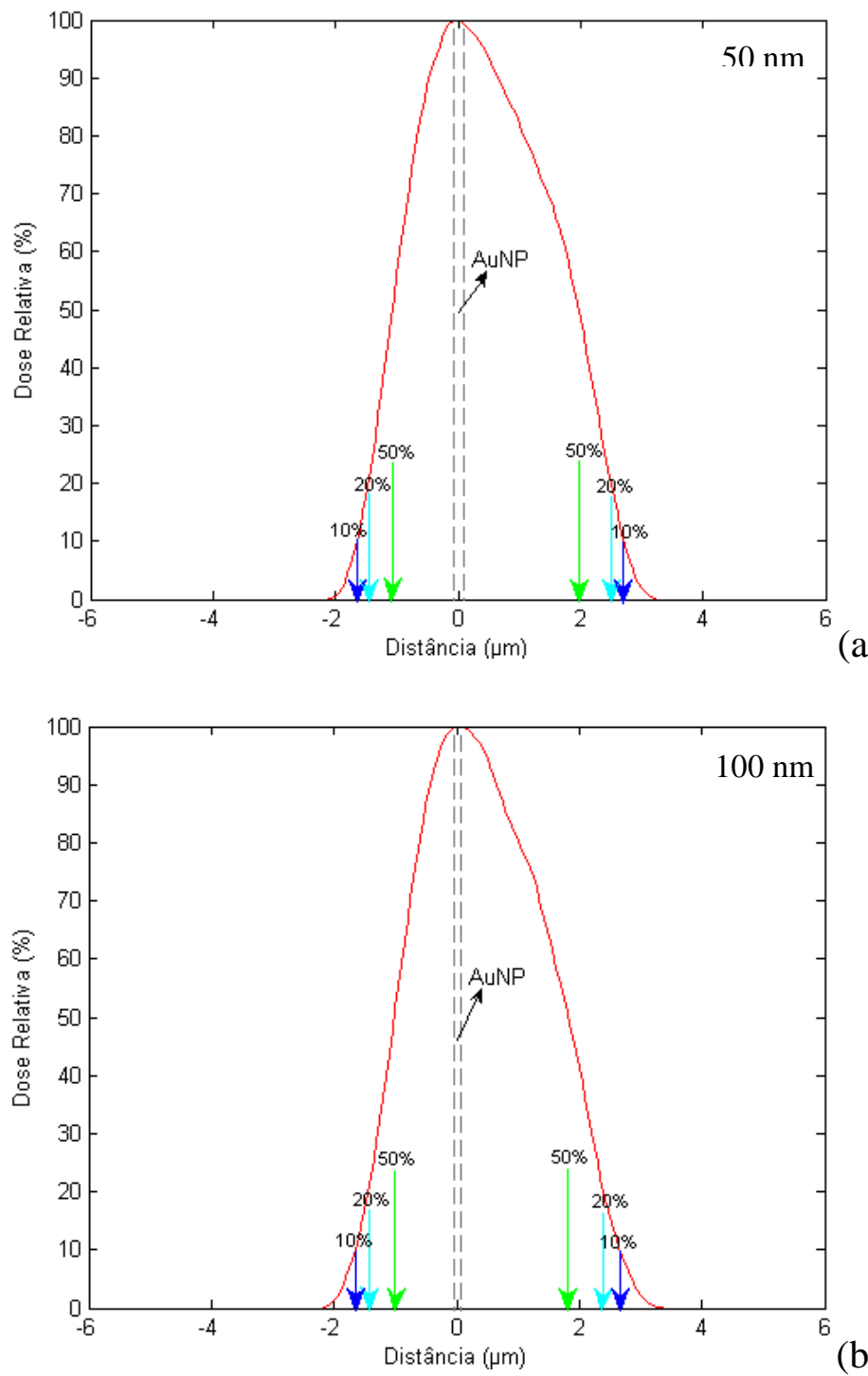

(b)

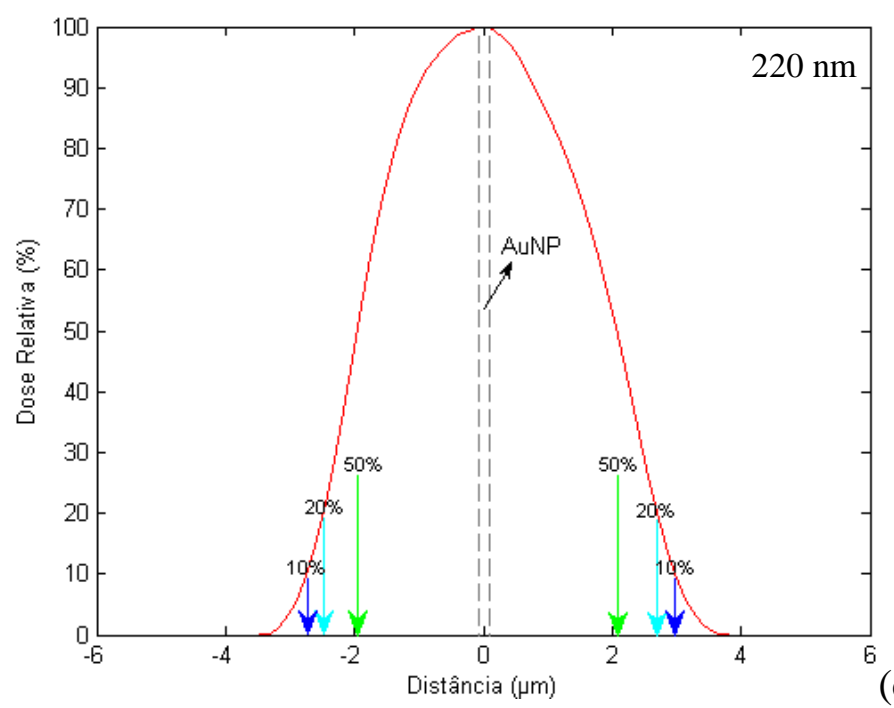

(c)

Figura 31: Perfis de doses para modelo heterogêneo com AuNP única e feixe de 50 kVp: (a) $50 \mathrm{~nm}$, (b) $100 \mathrm{~nm}$ e (c) $220 \mathrm{~nm}$. 

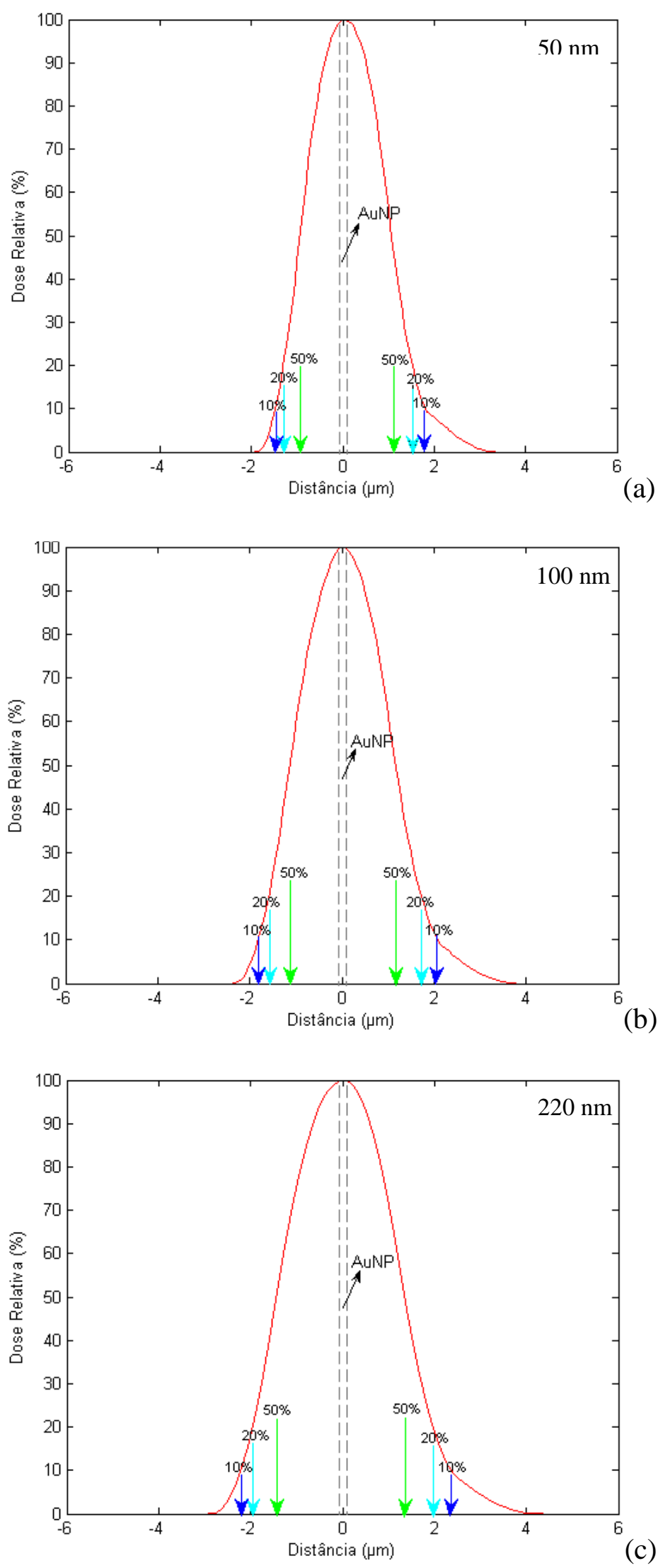

Figura 32: Perfis de doses para modelo heterogêneo com AuNP única e feixe de 150 kVp: (a) $50 \mathrm{~nm}$, (b) $100 \mathrm{~nm}$ e (c) $220 \mathrm{~nm}$. 

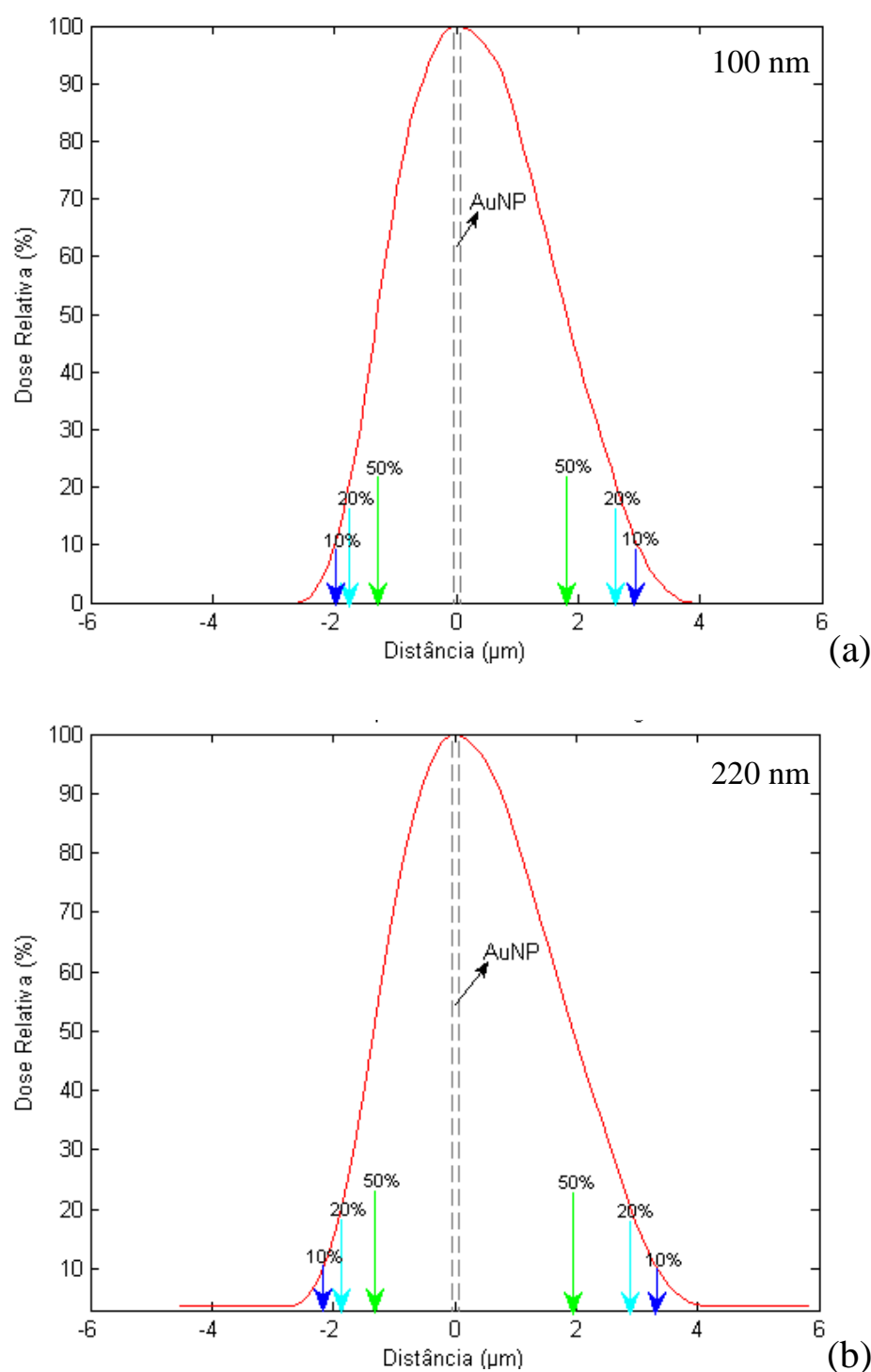

Figura 33: Perfis de doses para modelo heterogêneo com AuNP única e feixe de ${ }^{192}$ Ir: (a) $100 \mathrm{~nm}$ e (b) $220 \mathrm{~nm}$.

De modo geral, nota-se que o aumento de dose local pode atingir alguns micrômetros de distância da AuNP, dependendo da energia utilizada. Os feixes simulados apresentam diferentes fluências de energia, podendo produzir diferentes efeitos de interação e partículas secundárias em uma grande gama de energias e alcances. Os fotoelétrons que podem ser produzidos nos arredores das linhas K e L do ouro têm alcances, em trajetórias de perda de energia contínua, na água de, aproximadamente, 2 à $100 \mu \mathrm{m}$ (aproximação CSDA, do inglês Continuous Slowing Down Approximation). Os elétrons de 10 a $20 \mathrm{keV}$, mostrados na Figura 22 e encontrados nas fluências ejetadas por AuNPs para o feixe de $50 \mathrm{keV}$, têm alcance CSDA na água de 2,5 a $8,5 \mu \mathrm{m}$. Os elétrons Compton produzidos no ouro pelo feixe 
incidente de $150 \mathrm{keV}$, conforme mostrado na Figura 24, têm alcance CSDA na água de 2,5 $\mu \mathrm{m}$, para $10 \mathrm{keV}$, e 35 a $80 \mu \mathrm{m}$, aproximadamente, para 45 a $70 \mathrm{keV}$. Já os elétrons produzidos pelas AuNPs irradiadas com ${ }^{192} \mathrm{Ir}$, mostrados na Figura 25, terão alcances CSDA na água de, aproximadamente, $2,5 \mu \mathrm{m}$ a $1 \mathrm{~mm}$. Entretanto, a obtenção de perfis de dose com alcances efetivos máximos de até, aproximadamente, $4 \mu \mathrm{m}$ é condizente com a expectativa de que a perda de energia dos elétrons não seja contínua, especialmente para os elétrons de baixas energias produzidos nas AuNPs.

Das Figuras 31 a 33 nota-se, ainda, que os perfis não são simétricos em todas as combinações de tamanho de nanopartícula e feixe de radiação. Em geral, os perfis de dose são mais abertos na direção de coordenadas positivas da geometria de simulação, que representam regiões entre a entrada do feixe e a nanopartícula. Isso ocorre pois os perfis de dose são relativos à dose total, dada pela somatória da dose devida apenas à atenuação do feixe primário e da dose devida à contribuição das AuNPs. Assim, em profundidades menores, na região anterior à AuNP, a contribuição da dose primária é maior que na região após a nanopartícula, distorcendo os perfis. A exceção a esse padrão geral é observada para o feixe de $150 \mathrm{kVp}$, em que nota-se uma maior simetria nos perfis de dose. Isto possivelmente ocorre pela incerteza estatística das simulações de distribuição de doses na combinação da posição (profundidade) das AuNPs e energia do feixe em questão.

Os alcances das isodoses de 50, 20 e 10\%, no entorno das AuNPs e na direção paralela ao eixo do campo de radiação, são apresentadas na Tabela 5, sendo que para cada tamanho de AuNP foi avaliada a posição da isodose antes (lado da entrada do feixe) e depois (lado da saída do feixe) da nanopartícula. As incertezas nos alcances das isodoses são dadas pela metade do tamanho dos voxels utilizados em cada simulação, sendo de 25, 25 e $55 \mathrm{~nm}$ para as AuNPs de 50, 100 e $220 \mathrm{~nm}$, respectivamente. 
Tabela 5: Alcance das isodoses em torno das AuNPs no modelo heterogêneo com nanopartícula única.

\begin{tabular}{|c|c|c|c|c|c|c|c|}
\hline \multirow{3}{*}{ Energia } & \multirow{3}{*}{$\begin{array}{c}\text { Isodose } \\
(\%)\end{array}$} & \multicolumn{6}{|c|}{ Diâmetro das AuNPs } \\
\hline & & \multicolumn{2}{|c|}{$50 \mathrm{~nm}$} & \multicolumn{2}{|c|}{$100 \mathrm{~nm}$} & \multicolumn{2}{|c|}{$220 \mathrm{~nm}$} \\
\hline & & $\begin{array}{c}\text { Esquerdo } \\
(\mu \mathrm{m})\end{array}$ & $\begin{array}{c}\text { Direito } \\
(\mu \mathrm{m})\end{array}$ & $\begin{array}{c}\text { Esquerdo } \\
(\mu \mathrm{m})\end{array}$ & $\begin{array}{c}\text { Direito } \\
(\mu \mathrm{m})\end{array}$ & $\begin{array}{c}\text { Esquerdo } \\
(\mu \mathrm{m})\end{array}$ & $\begin{array}{c}\text { Direito } \\
(\mu \mathrm{m})\end{array}$ \\
\hline \multirow{3}{*}{$50 \mathrm{kVp}$} & 50 & 1,08 & 1,95 & 1,03 & 1,82 & 1,93 & 2,03 \\
\hline & 20 & 1,47 & 2,50 & 1,45 & 2,40 & 2,47 & 2,69 \\
\hline & 10 & 1,65 & 2,70 & 1,65 & 2,65 & 2,75 & 2,97 \\
\hline \multirow{3}{*}{$150 \mathrm{kVp}$} & 50 & 0,93 & 1,08 & 0,75 & 0,73 & 1,49 & 1,37 \\
\hline & 20 & 1,30 & 1,50 & 1,10 & 1,12 & 1,93 & 1,98 \\
\hline & 10 & 1,48 & 1,80 & 1,23 & 1,33 & 2,20 & 2,31 \\
\hline \multirow{3}{*}{${ }^{192} \mathbf{I r}$} & 50 & - & - & 1,31 & 1,80 & 1,38 & 1,93 \\
\hline & 20 & - & - & 1,76 & 2,63 & 1,87 & 2,86 \\
\hline & 10 & - & - & 1,99 & 2,96 & 2,15 & 3,30 \\
\hline
\end{tabular}

Para a região anterior à nanopartícula, pode-se observar que o alcance de influência das AuNPs na dose local varia com a combinação entre o seu tamanho e a energia do feixe, conforme esperado de acordo com os resultados obtidos para as fluências de elétrons ejetados para o meio biológico. Os maiores alcances das isodoses ocorrem, em geral, para o feixe de $50 \mathrm{kVp}$, com valores próximos aos obtidos para o feixe de ${ }^{192}$ Ir. Isto ocorre pela produção de elétrons de baixas energias pela AuNP para esses dois feixes, conforme mostrado nas Figuras 22 e 26. Já para o feixe de 150 kVp, obtiveram-se os aumentos de doses mais localizados entre os três feixes estudados, dados pela combinação da baixa fluência de elétrons ejetados e suas energias intermediárias, conforme mostrado na Figura 24.

De modo geral, os resultados mostram que um feixe de $50 \mathrm{kVp}$, em conjunto com AuNPs (ou aglomerados de AuNPs) de 50 a $220 \mathrm{~nm}$, proporciona DEFs significativos e reforços de dose localizados, de até, aproximadamente, $3 \mu \mathrm{m}$. Essas características são favoráveis para possíveis aplicações clínicas, desde que essas nanopartículas podem ser incorporadas no núcleo celular, reforçando significativamente a dose e aumentando a sensibilização celular pela geração de partículas carregadas no entorno do DNA. 


\subsubsection{Modelo heterogeneo com vários clusters de Nanopartículas}

Para uma modelagem mais realística da aplicação de AuNPs em radioterapia, foram obtidas a distribuição de doses e o DEF para uma célula com vários aglomerados de AuNPs.

A figura 34 apresenta a distribuição de dose para célula com vários aglomerados de AuNPs internalizados no núcleo e sendo irradiada com um feixe de $50 \mathrm{kVp}$. Nesta avaliação foram considerados 2 aglomerados de cada tamanho dentro do núcleo, com 50 $\mathrm{nm}, 100 \mathrm{~nm}, 150 \mathrm{~nm}$ e $220 \mathrm{~nm}$ de diâmetro. As doses foram normalizadas pela dose obtida no interior do aglomerado de $220 \mathrm{~nm}$ posicionado na parte superior do conjunto, de modo a melhorar a visualização da figura. Pode-se observar nessa figura que as esferas que representam os aglomerados de AuNP de $220 \mathrm{~nm}$ de diâmetro são as mais visíveis, devido à grande dose depositada no interior dessas nanopartículas. Nota-se, ainda, mesmo que qualitativamente, que os reforços de dose de cada aglomerado é local, como obtido anteriormente.

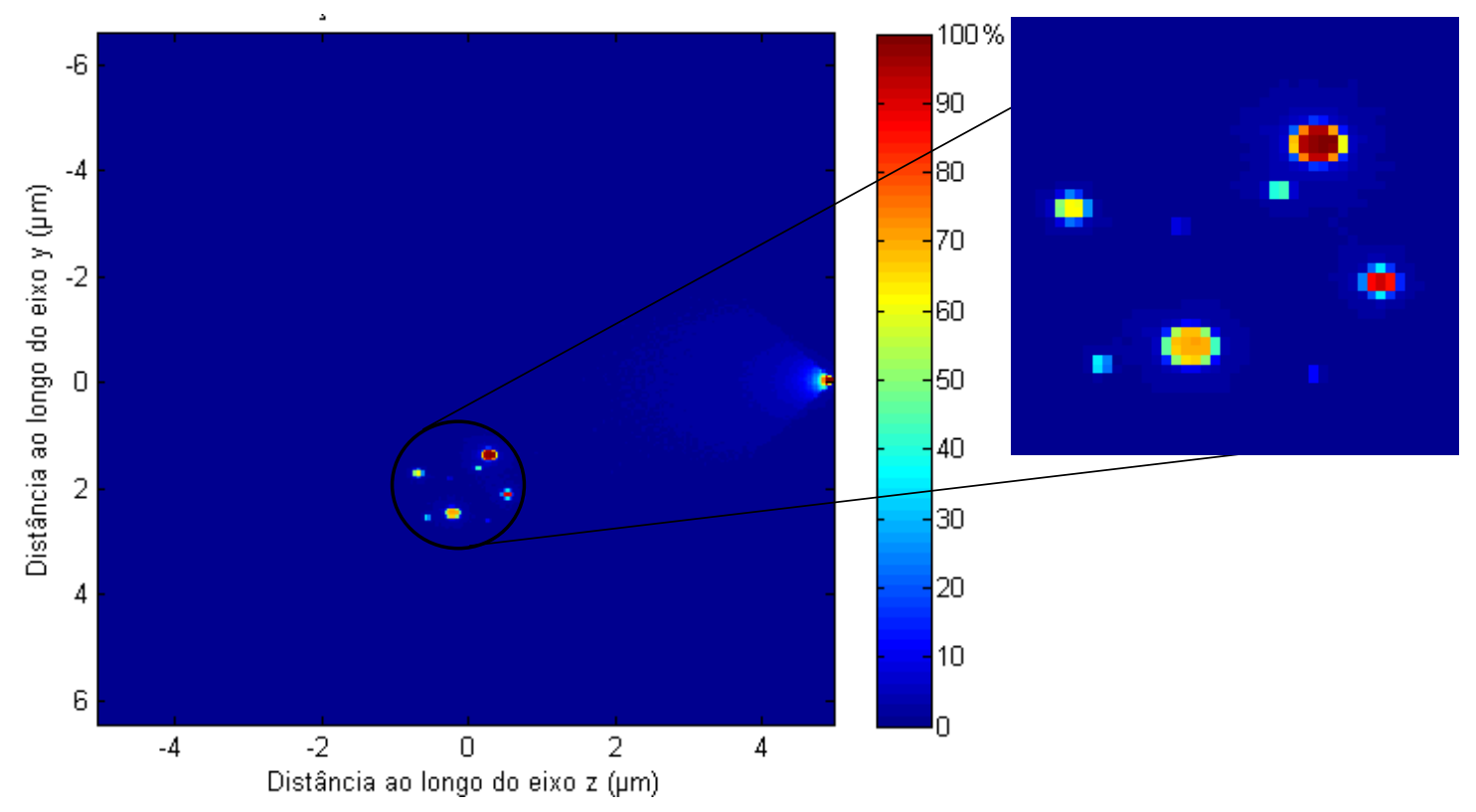

Figura 34: Distribuição de doses para célula com diferentes tamanhos de aglomerados de AuNPs no núcleo e irradiada com feixe de $50 \mathrm{kVp}$. 
Com todos os aglomerados de AuNPs de diferentes tamanhos distribuídos de forma heterogênea na célula foi possível avaliar o fator de aumento de dose para o feixe de 50 kVp em uma condição realística de incorporação de AuNPs em células tumorais. O DEF obtido no núcleo foi de $1,79 \pm 0,007$, sendo potencialmente significativo para aplicação clínica.

Além do reforço da dose, que pode se traduzir em maior efeito biológico, a fluência de partículas secundárias obtida com o feixe de $50 \mathrm{kVp}$ e a possibilidade de encontrar esses tamanhos de aglomerados no núcleo das células pode proporcionar efeitos sinergéticos que contribuam para o controle tumoral. Além do aumento de dose, há o aumento da efetividade radiobiológica da radiação secundária produzida, tanto pelo tipo quanto pela energia, e o aumento da probabilidade de produção de danos letais pela proximidade do DNA.

Desta forma, as AuNPs podem proporcionar a efetiva radiossensibilização tumoral. A radiossensibilização proporcionada pelas nanopartículas incorporadas ao tumor pode, ainda, ser potencializada através da escolha do material, tamanho, forma, concentração e funcionalização das mesmas, além da escolha do feixe de radiação. Essa combinação de características pode, ainda ser utilizada para proporcionar uma conformação micrométrica das doses de radiação, aumentando não apenas o controle tumoral, como auxiliando, ainda, na diminuição de efeitos adversos do tratamento.

Dado que feixes de radiação de megavoltagem, largamente utilizados em teleterapia para uma grande gama de tumores, produzem DEFs significativamente menores que os feixes de baixas energias, a maior potencialidade do uso de AuNPs para radiossensibilização e controle tumoral parece ser encontrada para aplicações em tumores superficiais ou para braquiterapia, ambos com o uso de feixes de energias na faixa de quiloeletronvolts.

Em todos os casos estudados neste trabalho, supôs-se que a radiossensibilização seria dada por processos físicos. O desenvolvimento de radioterapia com nanopartículas, entretanto, tem evoluído, também, na direção do uso de nanopartículas portadoras de quimioterápicos radiossensibilizadores e do desenvolvimento de nanopartículas inteligentes, que deverão ajudar a compor o futuro do diagnóstico e tratamento oncológico (Zang et al, 2017; Kannan et al, 2014). 


\section{Conclusões}

Neste trabalho foram estudados aspectos físicos da utilização de nanopartículas de ouro em radioterapia. Foram avaliadas as fluências de partículas secundárias produzidas, as distribuições de doses e os fatores de aumento de dose proporcionados por AuNPs incorporadas em células tumorais em combinação com feixes clínicos.

A utilização de um modelo de incorporação homogênea das AuNPs nas células fornece uma meio rápido e simples de avaliação dos DEFs para diferentes concentrações de nanopartículas e feixes de radiação. Entretanto, a utilização de um modelo de incorporação mais realístico, heterogêneo, é fundamental para a avaliação dos potenciais efeitos de aumento de doses locais das nanopartículas. O modelo heterogêneo de incorporação de AuNPs nas células permite, ainda, o estudo da influência das características físicas das nanopartículas, como tamanho e posição, na produção de partículas secundárias e no reforço de dose.

Com base nos resultados obtidos no trabalho conclui-se que os feixes clínicos com espectro na faixa de quiloeletronvolts proporcionam DEFs significativamente maiores que feixes de megavoltagem utilizados em teleterapia. Assim, vê-se uma maior potencialidade de uso de AuNPs em tratamentos superficiais, em braquiterapia com feixes de baixas energias ou, até mesmo, em aplicações em radioterapia intraoperatória.

Dada a característica local de reforço de dose pelas AuNPs, estas podem proporcionar, ainda, um fator de radiossensibilização tumoral se forem incorporadas no núcleo dessas células, nas redondezas do DNA. Assim, o uso de AuNPs de tamanhos apropriados para internalização no núcleo das células pode proporcionar um maior potencial de controle tumoral sem aumentar o efeito em tecidos normais, otimizando o efeito desejado do tratamento radioterapêutico. 


\section{Referências Bibliográficas}

André J P, De Sá A. O Rádio e a Medicina. Radioisótopos e Sociedade: O legado de Marie Curie 100 anos depois. Sociedade portuguesa de química, Departamento/Centro de Química, Universidade do Minho,2011.

Allison J, Amako J, Apostolakis H, et al. Geant4 developments and applications, IEEE Transactions on nuclear science, v. 53 (1), p. $70-78,2006$.

Albanese, A.; Tang, P.S. e Chan, W. C.W.: The effect of nanoparticle size, shape, and surface chemistry on biological systems. Annu. Ver. Biomed. Eng. v. 14, p. 1-16, 2012.

Alkilany, A.M. e Murphy, C.J.: Toxicity ans cellular uptake of gold nanoparticles: what have we leraned so far? J. Nanopart. Res. v. 12, p. 2313-2333, 2010.

Attix, F. H.: Introduction to radiological physics and radiation dosimetry. WILEYVCH Verlag GmbH \& Co. KGaA, 2004.

Barua, S. e Mitragotri, S.: Challenges associated with Penetration of Nanoparticles across Cell and Tissue Barriers: A Review of Current Status and Future Prospects. Nano Today, v. 9, p. 223-243, 2014.

Beddoes, C.M., Case, C.P., Briscoe, W.H., Understanding nanoparticle cellular entry: A physicochemical perspective. Advances in Colloid and Interface Science, v. 218, p. 48-68, 2015.

Bielajew A F, Rogers D W O. A standard timing benchmark for EGS4 Monte Carlo calculation, Med. Phys. v. 19 (2), pp. 303 - 304, 1992.

Brown, S.; Detwiler, R. S.; Baciak, J. E. et al: Utilization of MCNP for the development of spectral stripping algorithms for orthovoltage radiation therapy systems. Nuclear Instruments and Methods in Physics Research. v. 652, p. 726-730, 2011.

Chithrani, D.B.; Jelveh, S.; Jalali, F. et al: Gold nanoparticles as radiation sensitizers in cancer therpy. Rad. Research. v. 173, p. 719-728, 2010.

Cho, S.H.: Estimation of tumor dose enhancement due to gold nanoparticles during typical radiation treatments: A preliminary Monte Carlo study. Med. Phys. v. 32, p.2162-2162, 2005.

Cho, S.H.; Jones, B.L. e Krishnan, S.: The dosimetric feasibility of gold nanoparticleaided radiation therapy (GNRT) via brachytherapy using low-energy gamma/x-ray sources. Phys. Med. Biol. v. 54, p. 4889-4905, 2009.

Daehring, H.; Grandke, J.; Teichgraeber, U. et al: Improved hyperthermia treatment of tumors under consideration of magnetic nanoparticle distribution using micro-CT imaging. Molecular Imaging and Biol. v.17, p. 763-769, 2015. 
Dearling, J.L. e Packard, A.B.: Molecular imaging in nanomedicine - A developmental tool and a clinical necessity. J. Control. Release. v. 261, p. 23-30, 2017.

Dutreix, J; Dutreix, A: Henri Becquerel (1852-1908). American Association of Physicists in Medicine. v. 22, p. 1869-1875, 1995.

Douglass, M.; Bezak, E;Penfold, S.: Development of a randomized 3D cell model for Monte Carlo microdosimetry simulations. Med. Phys. v. 39, p. 3509-3519, 2012.

Grabbe, S.; Landfester, K; et al: Nanoparticles and the immune system: challenges and opportunities. Nanomed. v. 11, p. 2621-2624, 2016.

Haque, F.; Wang, S.W. et al: Advances in nanopore sensing promises to transform healthcare. Nanomed. v. 12, p. 1907-1909, 2017.

Hao, Y.; Zhang, B.; Zheng, C. et al: The tumor-targeting core-shell structured DTXloaded PLGA@Au nanoparticles for chemo-phototermal therapy and X-ray imaging. J. Controlled Release, v. 220, p. 545-555, 2015.

Hauser, A.K.; Wydra, R.J.; Stocke, N.A. et al: Magnetic nanoparticles and nanocomposites for remote controlled therapies. J. Controlled Release, v. 2019, p. 7694, 2015.

Hendrikcs, J. S.; Adams, K. J.; Booth T. E.: Present and future capabilities of MCNP.Applied Radiation and Isotopes, vol. 53, pp. 857 - 861, 2000.

Her, S.; Jaffray, D. A.; Allen, C.: Gold nanoparticles for applications in cancer radiotherapy: Mechanisms and recent advancements. Advanced Drug Delivery Reviews, v. 109, p. 84-101, 2015.

Huynh, E. e Zheng, G.: Cancer nanomedicine: addressing the dark side of the enhanced permeability and retention effect. Nanomed. v. 10, p. 1993-1995, 2015.

Iyer, A.K.; Khaled, J.; Fang, J. et al: Exploiting the enhanced permeability and retention effect for tumor targeting. Drug Discovery Today. v. 11, p. 812-818, 2006.

Jain, K.K.: Future of nanomedicine: impact on healthcare and society. Nanomed. v. 10, p. 3199-3202, 2015.

Johns, H. E. eCunninghan, J. R.: Physics of radiology. Charles C Thomas - Publisher, 1983.

Jones, B. L.; Krishnan, S.; e Cho, S. H.: Microscopic dose enhancement factor around gold nanoparticles. Am. Assoc. Phys. Med.v.37(7), p. 3809-3816, 2010.

Kannan, R.M., Nance, E. et al: Emerging concepts in dendrimer-based nanomedicine: from design principles to clinical applications. J. Internal Med. v. 276, p. 579-617, 2014. 
Kapadia, C.H.; Perry, J.L.; Tian, S. et al: Nanoparticulate immunotherapy for cancer. J. Controlled Release, v. 2019, p. 167-180, 2015.

Khan, F. M. e Gibbons, J. P.: The Physics of Radiation Therapy. Lippincott Williams \& Wilkins, 2014.

Kobayashi, H; Watanabe, R. e Choyke, P.L.: Improving conventional Enhanced Permeability and Retention (EPR) effects; what is the appropriate target?.Theranostics, v. 4, p. 81-89, 2014.

Koger, B. e Kirkby, C.: Optimization of photon beam energies in gold nanoparticle enhanced arc radiation therapy using Monte Carlo methods. Phys. Med. Biol. v.61,p.8839-8853, 2016.

Kubischok, N.:Assessing the future: past and present visions of nanomedicine. Nanomed. v. 10, p. 3195-3197, 2015.

Lechtman, E.; Chattopadhyay, N.; et al: Implications on clinical scenario of gold nanoparticle radiosensitization in regards to photon energy, nanoparticle size, concentration and location. Phys. Med. Biol., v. 56, p. 4631-4647, 2011.

Lechtman, E.; Mashouf, S. et al: A Monte Carlo-based model of gold nanoparticle radiosensitization accounting for increased radiobiological effectiveness. Phys. Med. Biol. v.58, p.3075-3087, 2013.

Lee, K. J.; Shin, S.H., et al.: A strategy for actualization of active targeting nanomedicine practically functioning in a living body. Biomat. V. 141, p. 136-148, 2017.

Lim, Z.Z.J.; Bay, B.H. et al: Gold nanoparticle in cancer therapy. ActaPharmacologicaSinica. v. 32, p. 983-990, 2011.

Li, S.; Yi, J.; et al: Synthesis and characterization of three novel amphiphilic dextran self-assembled micelles as potential drug delivery system. J. Mat. Sci.v. 52, p. 1259312607, 2017.

Liu, Y.; Liu, X.;Li, Q. et al: The dependence of radiation enhancement effect on the concentration of gold nanoparticles exposed to low- and high-LET radiations. PhysicaMedica. v. 31, p. 210-218, 2015.

Maeda, H.; Wu, J. Sawa, T. et al: Tumor vascular permeability abd the EPR effect in macromolecular therapeutics: a review. J. Controlled Release. v. 65, p. 271-284, 2000.

Mundt, A. J. e Roeske, J. C.: Intensity Modulated Radiation Therapy: A Clinical Perspective. BC Decker Inc. London, 2005.

Marques Pinto, T.: Nanopartículas de ouro para Radioterapia com energia modulada. Tese. Universidade de São Paulo, 2013. 
Nichols, J.W. e Bae, Y.H.: Odyssey of a cancer nanoparticle: from injection site to site of action. Nano Today. v. 7, p. 606-618, 2012.

NIST a: ESTAR - Stopping-power and range tables for electrons. https://physics.nist.gov/cgi-bin/Star/e_table.pl: acessado em 27 de setembro de 2017.

NIST b: $\quad$ X-ray mass attenuation coefficients. https://physics.nist.gov/PhysRefData/XrayMassCoef/ElemTab/z79.html: acessado em 27 de setembro de 2017.

Otto, K.: Volumetric modulated arc therapy: IMRT in a single gantry arc. Med Phys. v. 35, p. 310-317, 2008.

Powathil, G.;Kohandel, M. et al.: Modeling the spatial distribution of chronic tumor hypoxia: implications for experimental and clinical studies. Computational and Methematical Methods in Medicine. v. 2012, 11 páginas, 2012.

Pianoschi, T. A.; Avaliação do código de simulação Monte Carlo PENELOPE para aplicações em geometrias delgadas e feixes de radiodiagnósticos. Dissertação (Mestrado) - Faculdade de Filosofia, Ciências e Letras de Ribeirão Preto da Universidade de São Paulo, Ribeirão Preto. p. 9-14, 2008.

Rosenschold, M.; Nilsson, P.; Knoos, T.: Kilovoltage X-ray dosimetry-an experimental comparison between different dosimetry protocols. Phys. Med. Biol. v. 53, p. 44314442, 2008.

Salvajoli, J. V.; Souhami, L.; Faria, S. L.: Radioterapia em oncologia. Editora Atheneu, $2^{a}$ edição, São Paulo, 2013.

Salvat F.; Fernandez-Varea J. M.; Sempau, J.:PENELOPE-2008: A Code System for Monte Carlo Simulation of Electron and Photon Transport, Nuclear energy agency, Spain, 2008.

Schuemann, J.; Berbeco, R.; et al: Roadmap to clinical use of gold nanoparticles for radiation sensitization. Int. J. Rad. Oncol. Biol. Phys. v. 94, p. 189-205, 2016.

Seco, J. e Verhaegen, F.: Monte Carlo Techniques in Radiation Therapy. Taylor and Francis Group. Boca Raton, 2013.

Sempau, J.; Acosta, E.et al.: An algorithm for Monte Carlo simulation of coupled electron-photon transport. Nuclear Instruments and Methods in Physics Reasearch, v. 132, p. $377-390,1997$.

Sengupta, J.; Ghosh, S.; et al: Physiologically Important Metal Nanoparticles and Their Toxicity. J. Nanosc. Nanotech. V. 14, p. 990-1006, 2014..

Shang, L.; Nienhaus, K. e Nienhaus, G.U.: Engineeres nanoparticles interacting with cells: size matters. J. Nanobiothechnology. v. 12, 5 páginas, 2014. 
Sheikh-Bagheri, D.; Rogers, D. W. O.:Monte Carlo calculation of nine megavoltage photon beam spectra using the BEAM code. Med. Phys. v. 29, p. 391-402, 2002.

Sung, W.; Jung, S.; Ye, S.:Evaluation of the microscopic dose enhancement for nanoparticle-enhanced Auger therapy.Phys. Med. Biol. v.61, p. 7522-7535, 2016.

Sung, W. M.; Ye, S. J.; et al.: Dependence of gold nanoparticle radiosensitization on cell geometry. Nanoscale. v. 9, p. 5843-5853, 2017.

Stapleton, S; et al: Radiation effects on the tumor microenvironment: Implications for nanomedicine delivery. Adv. Drug Deliv. Rev. v. 109, p. 119-130, 2017.

Tu, Z.;Achazi, K. et al: Combination of Surface Charge and Size Controls the Cellular Uptake of Functionalized Graphene Sheets. Adv. Func. Mat. v. 27, n. 1701837, 2017.

Wagner, L. K.; Eifel, P. J.; Geise, R. A.: Potential Biological Effects Following High Xray Dose Interventional Procedures. JVIR, v.5 p.71-84, 1994.

Wang, H.; Yu, J.H.; et al: Nanoparticle systems reduce systemic toxicity in cancer treatment. Nanomed. v. 11, p. 103-106, 2016.

Webster, T: Nanomedicine: what's in a definition. Int. J. Nanomed. v. 1, p. 115-116, 2006.

Wilhelm, S.; Tavares, A.J.; et al: Analysis of nanoparticle delivery to tumours. Nature Rev. Mat. v. 1(3), (online) maio 2016.

Yurkin, S. T. e Wang, Z.: Cell membrane-derived nanoparticles: emerging clinical opportunities for targeted drug delivery. Nanomed. v. 12, p. 2007-2019, 2017.

Zang, L.R.; Li, R.T. et al: Human cytotoxic T-lymphocyte membrane-camouflaged nanoparticles combined with low-dose irradiation: a new approach to enhance drug targeting in gastric cancer. Int. J. Nanomed. v.12, p. 2129-2142, 2017.

Zilio, O. V.; Joneja, O. P.; Chawla, R. et al.: Dosimetric characterization of radioactive sources employed in prostate cancer therapy. Brachytherapy, v. 3, p. 201-214, 2004. 